\title{
Coupled thermo-physical behaviour of an inorganic intumescent system in cone calorimeter testing
}

\author{
Sungwook Kang ${ }^{1}$, Sengkwan $\mathrm{Choi}^{1}$ and J.Yoon $\mathrm{Choi}^{2}$
}

\begin{abstract}
This paper examines the thermo-physical behaviour of an inorganic-based intumescent coating, tested with bench-scale cone calorimetry, in order to promote the understanding of its intumescence and to contribute to the optimisation of its thermal insulation performance. In the test, the specimen underwent the following phenomena simultaneously: (i) Thermo-kinetic endothermic water vaporisation; (ii) Formation of micro-scale pores in its internal volume; (iii) Expansion of its volume; and (iv) Variations in thermal boundaries. These simultaneous phenomena cause several changes in internalexternal conditions given to the test sample: (i) Loss of mass (water molecules); (ii) Reduction of effective thermal conductivity owing to its porous structure; (iii) Increase in length of the conductive heat transfer path across its expanding volume; (iv) Irradiance intensification and additional heat transfer generation on its moving boundaries, exposed to the heat source and surroundings. This interacting thermo-physical behaviour impedes the heat transfer to the underlying substrate. It is therefore comprehensively explained by finite element analysis, associated with the experimental data obtained from a thermogravimetric analyser, differential scanning calorimetry, electric furnace, and cone calorimeter tests. The numerical predictions agreed with the physical measurements with consistent accuracy, in terms of both histories of substrate temperature and coating-thickness expansion. This combined numerical-experimental approach enables clear interpretation on the process of intumescence, the impediment mechanism of heat transfer, and the critical factors of the material's behaviour.
\end{abstract}

\section{Keywords}

Inorganic intumescent coating, cone calorimeter, finite element analysis,

Date received: $\quad$; revised: $\quad$; accepted:

\footnotetext{
ISchool of the Built Environment, Ulster University, Jordanstown Campus, UK

2Fire Safety Team, Division of Built Environment, Korea Conformity Laboratories, Republic of Korea

Corresponding author:

Sengkwan Choi, School of the Built Environment, Ulster University, Jordanstown Campus, Shore Road, BT37 0QB, UK

Email: s.choi@ulster.ac.uk
} 


\begin{tabular}{|c|c|c|c|}
\hline \multicolumn{4}{|c|}{ Nomenclature } \\
\hline$A$ & surface area & Subscripts & \\
\hline$c$ & specific heat $(\mathrm{J} /(\mathrm{kgK}))$ & air & air \\
\hline$k$ & thermal conductivity $(\mathrm{W} /(\mathrm{mK}))$ & e & element \\
\hline$m_{\mathrm{e}}$ & mass of a fully dense element & eff & effective \\
\hline$\dot{q}^{\prime \prime}$ & heat flux $\left(\mathrm{W} / \mathrm{m}^{2}\right)$ & enve & envelope \\
\hline$T_{j}$ & $\begin{array}{l}\text { measure of temperature in TGA- } \\
\text { MS data }\end{array}$ & irr & irradiance \\
\hline$t_{\exp }$ & $\begin{array}{l}\text { Time at which elements are fully } \\
\text { expanded }\end{array}$ & loss & mass loss \\
\hline$V$ & volume & P_solid & solid particle \\
\hline$x, y, z$ & Cartesian coordinates & $s$ & substrate \\
\hline & & $v \_$gas & void filled with gas \\
\hline Greek & Imbols & w_stream & water stream \\
\hline$\alpha_{T}$ & thermal expansion coefficient & & \\
\hline$B$ & ratio of mass at $T_{j}$ to initial mass & Abbreviatic & \\
\hline$\gamma$ & $\begin{array}{l}\text { empirical ratio of volume expansion } \\
\text { in } \mathrm{x} \text {-direction to that in } \mathrm{z} \text {-direction }\end{array}$ & $C C$ & cone calorimeter \\
\hline$\varepsilon_{T}$ & thermal strain & DSC & $\begin{array}{l}\text { differential scanning } \\
\text { calorimetry }\end{array}$ \\
\hline$\ell$ & coating-thickness & $E F$ & electric furnace \\
\hline$\rho$ & density $\left(\mathrm{kg} / \mathrm{m}^{3}\right)$ & FEA & finite element analysis \\
\hline$\Phi$ & porosity & $\begin{array}{l}\text { SEM } \\
\text { TGA-MS }\end{array}$ & $\begin{array}{l}\text { scanning electron } \\
\text { microscope } \\
\text { thermogravimetric } \\
\text { analyser/mass spectrometer }\end{array}$ \\
\hline
\end{tabular}




\section{Introduction}

The intumescent-type fire retardant system has become increasingly popular as an effective means of passive fire protection for underlying structural members [1]. In order to promote the understanding of the behaviour of this type of material in fire, previous studies have attempted to mathematically model its intumescence and to verify their models experimentally, as well as to chemically improve its performance [2-5]. In the examination of such behaviours, the quantity of the net heat absorbed by the coatingsample is the critical information required. Cone calorimetry has therefore been adopted frequently, since this is acknowledged to be a bench-scale apparatus which can create a relatively well-controlled environment of radiant heating, in contrast to gas-fired burners and furnaces [6-8].

This project aims to examine the intumescence of a particular type of coating, subjected to the thermal condition produced by the cone calorimeter, in order to contribute to the comprehensive understanding and optimisation of its thermal insulation performance. This refractory material is composed of four major ingredients: Sodium silicate of $41.1 \mathrm{wt} \%$; Kaolinite of $42.3 \mathrm{wt} \%$; Aluminium oxide of $8.0 \mathrm{wt} \%$; and Titanium dioxide of $8.5 \mathrm{wt} \%$ [9]. It is categorised as an 'inorganic' (or mineral)-based intumescent coating [10-11]. Once this polymer compound is placed under the conical heater and activated at a critical temperature, it undergoes simultaneous thermo-physical phenomena, as illustrated in Figure 1:

- Endothermic decomposition reactions, specifically water vaporisations with dehydration and dehydroxylation [9], which result in (i) loss of mass (water molecules);

- Volume expansion, which leads to (ii) an increase in length of the conductive heat transfer path to the underlying substrate $(\ell)$, as shown in Figure 1(b), (iii) an intensification of irradiance on the coating's top surface, due to a decrease in the distance between the heater and the exposed surface area $(h)$, and (iv) a generation of additional heat transfers (convective loss, radiant emission and absorption) on the extended surface areas of the specimen's perimeter;

- Formation of porous structure in its internal volume, as illustrated in Figure 1(b), due to the water vaporisation and rapid migration of water molecules. It results in (v) a reduction of effective thermal conductivity, and (vi) a porosity distribution along the thickness of the expanded volume, owing to different levels of restrictions along the depth, in terms of vapour migration.

The six resultant physical responses interact with each other's progressions in each of the time increments, and therefore determine the fire retardant system's global behaviour at elevated temperatures (i.e., intumescence).

The interacting thermo-physical behaviour of the inorganic intumescent coating is numerically analysed in this paper. The establishment of the methodology for modelling this behaviour is found on the key findings from existing researches on the development of theoretical models of intumescence:

- Pioneering studies [12-13], conducted in the 1970s, emphasised the importance of the thermal environment and boundary conditions, being subjected to the solution 
domain, in designing a semi-empirical analytical model. This implies that accurate quantities of heat, incoming to and outgoing from the exposed surfaces of the coating-sample (i.e., thermal boundaries), need to be applied in simulations;

- Another early research group [14-15] and a succeeding study [16] claimed that the intumescence occurs over a finite range of temperature, rather than at a specific level of temperature. Relating to this assertion, it was claimed that endothermic decomposition reactions, to a greater or lesser extent, occur simultaneously over the coating-thickness, depending on the creation of a temperature gradient [17-18]. This indicates that layers at different stages, such as charred, expanding, and virgin (initial) states, coexist along the coating-thickness at any one time after heating, as presented by a research group [19-21]. In their studies, a noticeable observation demonstrated that the size of pores and the degree of expansion are not also homogenous over the expanded thickness. Another study performed a Scanning Electron Microscope (SEM) observation, showing that porosity and pore-size are not uniform across expanded char [22-23]. These series of non-uniform/-linear distributions (of temperature, decomposition reaction, pore-size, porosity, and degree of volume expansion) along the expanding coating-thickness need to be included in numerical simulations. In addition, the coating's volume expansion should be interpreted from the mechanism of endothermic decomposition reactions;

- The mathematical model developed by the research group [17-18] was controlled by two empirical variables: The fraction of volatile and the volume expansion factor. This model functioned based on the assumption that the apparent (or envelope) density of control volume varies with the expansion of volume. The initial and final thicknesses of coatings, density, and volatile release (mass loss) were regarded as the dominant parameters in their simulations. The findings indicate that the determination process of an expansion factor, applicable for a given intumescent material, should be appropriately established in association with changes in envelope density and mass;

- In explaining and simulating the mechanism of intumescence, attention was also paid to effective thermal conductivity $\left(k_{\text {eff }}\right)[19-21,24]$. The expanding coating can be considered as a category of porous media, and the measure $k_{\text {eff }}$ represents the medium's ability to transport heat. In its determination, the previous studies [25-27] adopted one of specialised models for the mechanism of heat transfer in porous media, specifically Russell model [28], instead of using the fundamental models, such as series and parallel configurations of solid and void phases. The contribution of radiation to $k_{\text {eff }}$ was also considered, and the size of the maximum bubble was regarded as a decisive variable. In Staggs' studies [22-23, 29-30], a range of $k_{\text {eff }}$ was proposed from two applicable outermost cases, instead of defining a single value for $k_{\text {eff }}$. With regard to this measure, a clear interpretation of its determination is required in the course of numerical simulations.

The existing studies have contributed to the identification of the factors critical for the success of theoretical modelling of intumescence, which can be highlighted as follows: (i) Thermal boundaries; (ii) Nonlinear distribution of temperature along coating-thickness; 
(iii) Intumescence coupled with heat absorption and mass loss; (iv) Inconsistent degrees of expansion along coating-thickness; and (v) Effective thermal conductivity. However, those works either neglected some of the highlighted points in their modelling or provided insufficient interpretations of the key sub-topics, with the result that there still existed disagreements between theoretical predictions and physical measurements. Further examinations therefore need to be performed, based on the principles specialised for the sub-topics, such as thermo-kinetics, radiative view factor, combined heat transfer in porous media (via conduction, convection, and radiation), and thermal expansion.

This work develops a numerical approach into which the critical factors introduced are integrated. In order for a more sophisticated predictive model to work, an infinitesimal element of the polymer compound is considered to be a unit solution-domain. Its 'local' thermo-physical behaviour is initially defined and applied to the simulation of the 'global' behaviour of layered elements (i.e., multi-layer). Specifically, (i) a series of sequential actions of the element's mass and volume changes are theoretically developed based on experimental data; (ii) the multi-layer's behaviour in proposed sequence is numerically simulated by employing a Finite Element Analysis (FEA) software (i.e., ABAQUS/Standard) with user subroutines; and (iii) the numerical predictions are validated by experimental measurements. There have been several efforts to examine a complex mechanism of heat transfer through porous media using the FE method [22, 31 and 32]. No FEA model of intumescence was found in existing studies. The FE approximation is more accurate and efficient as a numerical solution in the proposed model than the widely used Finite Difference (FD) and Finite Volume (FV) methods. This 'piecewise' approach benefits analyses of thermo-physical behaviours of intumescent systems with nonlinear properties and the conditions of moving boundaries and nonlinear thermal boundaries, as compared to the 'pointwise' FD approximation [33].

\section{Experimental methods and results}

Several bench-scale tests were conducted (i) to understand the thermo-kinetic characteristics of the inorganic intumescent coating, (ii) to obtain its thermo-physical properties, (iii) to topologically analyse its internal structure, and (iv) to verify numerical predictions, by utilising Thermogravimetric Analyser/Mass Spectrometer (TGA-MS), Differential Scanning Calorimetry (DSC), Electric Furnace (EF) and Cone Calorimetry (CC) [34]. The critical data physically measured from the tests are shown in Figure 2.

For TGA-MS and DSC tests, samples of the polymer compound were fully dried at room temperature. A mass in the range of $10 \mathrm{mg}$ to $30 \mathrm{mg}$ was placed in both the apparatuses, and heated to approximately $1000{ }^{\circ} \mathrm{C}$ at a constant rate of $10{ }^{\circ} \mathrm{C} / \mathrm{min}$ in a nitrogen atmosphere. In Figure 2(a), the solid curve indicates the recorded mass loss according to temperature in percentage, while the symbols show the chromatograms of the gas mixture released: Hydrogen oxide $\left(\mathrm{H}_{2} \mathrm{O}\right)$ and Hydroxide $\left(\mathrm{OH}^{-}\right)$. It can be identified from the TGA-MS data that (i) the polymer compound has two major thermo-chemical decomposition reactions: Water vaporisations with dehydration and dihydroxylation; and (ii) any chemical degradations of the solid residue of the inorganic intumescent coating do not occur in the range of temperature, less than approximately $800{ }^{\circ} \mathrm{C}$. The thermal 
energy required for the activation of these endothermic reactions was measured from DSC tests, as shown in Figure 2(b).

A laboratory-scale EF with dimensions of $200 \mathrm{~mm}$ x $300 \mathrm{~mm}$ x $200 \mathrm{~mm}$ was utilised (i) to measure the envelope density (or porosity) of the coating under different temperature conditions, and (ii) to identify the distributions of porosity and pore-size along the expanded thickness. The top and perimeter surfaces of plain steel plates (70 mm x $70 \mathrm{~mm}$ x $5 \mathrm{~mm}$ in dimension) were coated with the inorganic intumescent material to a dry-film thickness (DFT) of $3 \mathrm{~mm}$. The prepared samples were fully dried at room temperature, and placed in the furnace which was heated to the designed levels of temperature, from $100{ }^{\circ} \mathrm{C}$ to $800{ }^{\circ} \mathrm{C}$ at intervals of $100{ }^{\circ} \mathrm{C}$, at a rate of $10^{\circ} \mathrm{C} / \mathrm{min}$. Once the thermal environment reached the designated temperatures, it was preserved for a while to succeed in achieving a thermal equilibrium between the furnace and the intumescent specimen placed.

It was observed that the fully expanded coating-residue was not a carbonaceous black char but a rigid white foam. The coating-residues obtained at different levels of temperature were horizontally sliced at intervals of $4 \mathrm{~mm}$ by utilising a high-speed cutter. The envelope density of each of the sliced segments, sampled from different geometrical positions along the expanded coating-thickness, was individually measured, as shown in Figure 2(c). It transpired that there was a growing tendency among the porosity $(\Phi)$ data in the range of 0.865 to 0.930 , gained at difference temperatures and the fully expanded state, according to the distance from the underlying steel substrate $(z)$. The data were thus averaged out to identify the relation between $\Phi$ and $z$, which are listed in Figure 2(d); the observed porosity, the region in which it was measured, and the proportions of the regions in percentage are henceforth referred to as the maximum porosity $\left(\Phi_{\max }\right)$, 'zone', and the proportion of zone ( $V_{\text {zone }}$ ), respectively. It is assumed based on this observation that when the inorganic intumescent material is heated by the cone calorimetry, its fully expanded specimen also reaches the observed distributions of $\Phi_{\max }$ and $V_{\text {zone, }}$ independent of the amount of fully expanded thicknesses. The true density of the solid particle at ambient temperature $\left(\rho_{p \_s o l i d}\right)$ was also measured at approximately $2077 \mathrm{~kg} / \mathrm{m}^{3}$. It is noted that although the EF test results contributed to the identification of the $\Phi_{\max }-Z$ relationship, the test process was not delicate enough to derive a relationship between temperature and porosity (the furnace temperature was adjusted at intervals of $100{ }^{\circ} \mathrm{C}$ ). This relation is therefore defined from a temperature-dependent sequence of mass and volume changes, based on the TGA-MS and DSC data, in this work.

For CC tests, plain steel plates (70 mm x $70 \mathrm{~mm}$ x $5 \mathrm{~mm}$ in dimension) were placed in the middle of a sample-holder (100 mm x $100 \mathrm{~mm}$ x $10 \mathrm{~mm}$ in dimension). The mouldable intumescent material was then carefully poured to make test-samples with no air pocket. The DFTs of the specimens were regulated at $2 \mathrm{~mm}, 3 \mathrm{~mm}$, and $4 \mathrm{~mm}$. Five thermocouples (k-type) were welded on the bottom surface of the steel substrate. The prepared specimens were irradiated at $35 \mathrm{~kW} / \mathrm{m}^{2}, 50 \mathrm{~kW} / \mathrm{m}^{2}$, and $65 \mathrm{~kW} / \mathrm{m}^{2}\left(\dot{\mathrm{q}}_{\mathrm{irr}}^{\prime \prime}\right)$ by the conical heater. From the CC tests, two sets of data were recorded via thermocouples, a video recorder, and a digital ruler, to verify numerical predictions. Figures 2(e) and (f) show the histories of (i) substrate temperature and (ii) the expansion of coating-thickness, at $\dot{\mathrm{q}}_{\mathrm{irr}}^{\prime \prime}=50 \mathrm{~kW} / \mathrm{m}^{2}$ and DFT=3 $\mathrm{mm}$. For analysis purposes, the development of the 
substrate temperature over time was compartmented in four stages, according to the state of system: (i) $1^{\text {st }}$ initial transient, (ii) $2^{\text {nd }}$ short plateau, (iii) $3^{\text {rd }}$ subsequent transient, and (iv) $4^{\text {th }}$ steady states.

\section{Determination of the critical issues}

The critical issues, highlighted in the part of Introduction, are individually discussed in this section.

\section{Thermal boundaries}

In this project, the thermo-physical behaviour of the inorganic intumescent coating is mainly examined through the cone calorimetry. Its behaviour is powered by the thermal energy supplied by the conical heater, and thus determined by the amount of the net heat absorbed at each time-increment. In the course of the testing, (i) the irradiance on the top surface of the heat-sensitive specimen is intensified, and (ii) the additional radiant flux is incident on its extended side (perimeter) surfaces, due to its moving boundaries underneath the heater which is geometrically stationary, as illustrated in Figure 3. To include the changes in thermal energy in numerical modelling, the quantities of the irradiances, varying according to the $z$ coordinates of the surface areas $\left(A_{1}\right.$ and $\left.A_{2}\right)$, were theoretically predicted by calculating view factors at each time-increment. The determined values were continually updated to FEA models by using user subroutines. The details regarding the derivation of view factor formulas were thoroughly discussed in the previous work [35].

In regard to the heat exchange on the specimen's sides, a two-dimensional (2-D) model was developed, as shown in Figure 4(a), in order to consider the effect of this heat transfer on the coating's behaviour in the primary z-direction. The prediction of this $\mathrm{x}-\mathrm{z}$ plane model therefore represents the behaviour of the 'square' specimen. This 2-D plane model yields the outcomes technically identical to those predicted by the 2-D wedge model of a cylindrical specimen, as illustrated in Figure 4(b). This is due to the fact that, during cone testing, irradiances being incident on the top and side surfaces are identical in the two models, based on the view factor maps as shown in Figure 3. For the same reason in terms of irradiance dispersions, the 2-D wedge model produces identical results, as compared to those obtained from a three-dimensional (3-D) quarter wedge model (Model I), as illustrated in Figure 4(c). Although Model I differs from the 3-D quarter model (Model II), extended from the original 2-D plane model, the difference between the results gained from Models I and II is minor, based on the deductions that (i) the amount of irradiance on Area A is much smaller than that on Area A'; (ii) the difference between the irradiances on Areas $\mathrm{B}$ and $\mathrm{C}$ is ignorable; and (iii) the difference between the heat losses through Areas $\mathrm{B}$ and $\mathrm{C}$ is minor. 3-D modelling of the interacting behaviour of the intumescent coating requires significant computational resources and time, due to a large number of elements and nodes. Hence, use of the 2-D plane model meets the requirements of both theoretical accuracy and computational efficiency. 
The coating's behaviour is determined from the combination of several interactants varying with the change of temperature: Thermal boundaries; specific heat (with sensible and latent heats, required for thermo-chemical reactions); thermo-kinetic mass loss; length of the conductive heat transfer path; porosity (or density); and the porous structure's ability to transfer heat (effective thermal conductivity). The coating's behaviour is therefore highly dependent on temperature.

In relation to this fact, the polymer's low conductivity and irregular internal structure creates a temperature gradient along its heat transfer path (thickness). It indicates that the temperature-dependent activation moment in time varies along the thickness. To simulate its sophisticated response to heat, the virgin coating was regarded as being a number of discrete and isothermal layers with an infinitesimal thickness, as shown in Figure 5. In this assumption, each of the elements is a 'continuum mixture' of solid and void, and acts individually in accordance with a temperature-dependent process of intumescence. The summation of the local behaviours of the solution domains resulted in a global behaviour of the coating in turn, where $t_{\text {exp }}$ refers to the instant at which all the layers are fully expanded. Based on this scheme, a temperature-dependent dynamic progress of intumescence took place during the simulations.

\section{Intumescence coupled with heat absorption and mass loss}

Intumescence originates from the release of molecules from blowing agents (watervapour) produced in the course of the endothermic decomposition reactions. These reactions are activated by the absorbed heat, and occur in a finite range of temperature, rather than at a particular temperature. The thermal quantity required for reactions is represented by Arrhenius parameters in conventional modelling, whilst in this work the essential temperature-dependent profiles of mass change and specific heat, measured by TGA-MS and DSC (Figures 2(a) and (b)), are directly used, in order to reduce the number of uncertain variables in numerical modelling.

A series of sequential actions of the $k$ th layer of the multi-layer virgin coating was initially developed, as shown in Figure 6. This sequence is composed of three steps:

STEP 1: When the fully dense layer with a constant mass $\left(m_{e}\right)$ and initial volume $\left(V_{p_{-} \text {solid }}\left(T_{0}\right)\right)$ at ambient temperature reaches critical temperature, it dehydrates part of its water molecules, indicating a mass loss, as follows:

$$
m_{\text {loss }}\left(T_{j}\right)=m_{p_{-} \text {solid }}\left(T_{j}\right)-m_{p_{-} \text {solid }}\left(T_{j-1}\right) \quad j=1,2,3, \cdots
$$

where $T_{j}$ refers to the measure of temperature in the TGA-MS data. The mass of the residual solid at each level of temperature is expressed as:

$$
m_{p_{-} \text {solid }}\left(T_{j}\right)=\beta_{T G A}\left(T_{j}\right) m_{e}
$$

where $\beta_{T G A}$ represents the ratio of the mass at $T_{j}$ to the initial mass, $m_{e}$, in percentage. 
STEP 2: The dehydrated molecules, $m_{\text {loss }}$, stay as liquid-water for an extremely short period of time. After absorbing sensible and latent heat, the liquid-water is vaporised. In the course of phase-change, the mass of water vapours occupies a greater volume space, as shown in Figure 6(a), due to its lower density than that of solid-particle. The volume of water vapours is defined as:

$$
V_{w_{-} \text {stream }}\left(T_{j}\right)=\frac{m_{\text {mass }}\left(T_{j}\right)}{\rho_{v_{-} \text {gas }}}
$$

where $\rho_{v_{\_} \text {gas }}$ represents the parametric density of gas filling pores.

STEP 3: It is assumed that the gaseous water-molecule with the lower density subsequently escapes into the atmosphere, and the void space is naturally reoccupied by the surrounding air with no changes in volume. The sum of the volumes of the air and residual solid is equivalent to the envelope volume at $T_{j}$ $\left(V_{\text {enve }}\left(T_{j}\right)\right)$. It indicates an increase in the volume (or thickness) of the $k$ th layer, in accordance with its mass loss. The changes in mass and volume occur at each level of temperature, as illustrated in Figure 6(b), which give:

$$
\begin{aligned}
V_{\text {enve }}\left(T_{j}\right) & =V_{p_{-} \text {solid }}\left(T_{j}\right)+\sum_{i=1}^{j} V_{\text {air }}\left(T_{i}\right) \\
& =\frac{\beta_{T G A}\left(T_{j}\right) m_{e}}{\rho_{p_{-} \text {solid }}}+\sum_{i=1}^{j} \frac{\left(\beta_{T G A}\left(T_{i}\right)-\beta_{T G A}\left(T_{i-1}\right)\right) m_{e}}{\rho_{v_{-} \text {gas }}}
\end{aligned}
$$

For description purposes, although the sequential changes of mass and volume are illustrated with discrete segments in series in Figure 6, the envelope volume of the $k$ th layer is in fact a homogeneous mixture of solid and air in numerical modelling. It is important to note that, in equation (4), $\rho_{v_{\_} \text {gas }}$ is the only unknown variable, which thus represents the degree of expansion of the $k$ th layer in this intumescence process. This variable is determined from parametric studies when a best-fit numerical prediction to experimental measurements is obtained, in terms of the coating's global behaviour.

To promote the accuracy of numerical predictions on the coating's thermo-physical behaviour, the designed sequential expansion in z-direction was extended to twodimensions on the $\mathrm{x}-\mathrm{z}$ plane, as shown in Figure 7. Specifically, the secondary volume change in $\mathrm{x}$-direction was considered in the calculation of the differential thicknessexpansion in the primary $z$-direction $\left(d \ell_{z}\left(T_{j}\right)\right)$ by:

$$
d \ell_{z}\left(T_{j}\right)=\frac{\sqrt{\left(\ell_{x}\left(T_{j-1}\right)+\gamma \ell_{z}\left(T_{j-1}\right)\right)^{2}+4 \gamma d V_{\text {enve }}\left(T_{j}\right)}-\left(\ell_{x}\left(T_{j-1}\right)+\gamma \ell_{z}\left(T_{j-1}\right)\right)}{2 \gamma}
$$

where

$$
\ell_{x \text { or } z}\left(T_{j}\right)=\ell_{x \text { or } z}\left(T_{j-1}\right)+d \ell_{x \text { or } z}\left(T_{j}\right), d \ell_{x}\left(T_{j}\right)=\gamma d \ell_{z}\left(T_{j}\right)
$$

The subscripts $x$ and $z$ indicate the $x$ and $z$ directions, while $\gamma$ refers to the empirical ratio of the volume expansion in $\mathrm{x}$-direction to that in $\mathrm{z}$-direction, which was measured as 0.1 [36]. The assumptions made for the derivation of the sequential changes in mass and volume as a function of temperature are summarised as follows:

- The elemental layer is infinitesimal, discrete, and isothermal;

- Once expanded, the layer does not shrink; 
- The three-dimensional 'volume' expansion is modelled as the two-dimensional 'area' expansion;

- The densities of solid particle, liquid water, and the air are constant and independent of temperature.

\section{Inconsistent degrees of expansion along coating-thickness}

In this work, the temperature-dependent volume expansion of the $k$ th layer was simulated by the FEA software, as logarithmic thermal strain $\left(\varepsilon_{T}\right)$ of the solution domain. It is represented by thermal expansion coefficient $\left(\alpha_{T}\right)$, as follows:

$$
\varepsilon_{T, z}=\alpha_{T, z} \Delta T=\ln \left(1+\frac{d \ell_{z}\left(T_{j}\right)}{\ell_{z}\left(T_{0}\right)}\right)
$$

To determine $\alpha_{T}$, equation (5) is substituted into equation (6), which gives:

$$
\alpha_{T, z}=\frac{1}{\Delta T} \ln \left(1+\frac{1}{2 \gamma \ell_{z}\left(T_{0}\right)}\left\{\begin{array}{l}
\sqrt{\left(\ell_{x}\left(T_{j-1}\right)+\gamma \ell_{z}\left(T_{j-1}\right)\right)^{2}+4 \gamma d V_{\text {enve }}\left(T_{j}\right)} \\
-\left(\ell_{x}\left(T_{j-1}\right)+\gamma \ell_{z}\left(T_{j-1}\right)\right)
\end{array}\right\}\right)
$$

Equation (7) is coupled with equation (4). This fact implies that $\alpha_{T}$ is in turn determined by $\rho_{v_{-} \text {gas }}$ representing the degree of expansion.

According to the proposed sequential process of intumescence, the 'local' thickness expansion of each of the zones originates from the loss of water molecules (Figure 2(a)) and is mainly induced by the increase in the air-filled space in its volume $\left(V_{a i r}\left(T_{j}\right)\right)$, as expressed in equation (4). Since the growth in void space indicates the increase in porosity, it transpired that this property is closely related to the degree of expansion of each of the zones.

With respect to the relationships among the thickness expansion, mass loss, and porosity, attention was paid to two observations: (i) There was a 'single' curve of mass loss, as shown in Figure 2(a); (ii) 'Multiple' porosities $\left(\Phi_{\max }\right)$ were observed along the thickness of the fully expanded coating-residue, as shown in Figure 2(d). These findings indicate that the local thickness expansion of each of the zones was determined by not only the TGA-MS datum but also its geometric position along the coating-thickness (in z-direction). In this regard, provided that the layered zones were uniformly heated and simultaneously reached a critical temperature, the lower layer would expand more than the upper one, due to a stronger level of restriction, in terms of water-vapour's internal migration towards outwards, as illustrated in Figure 8(a) ('expanding state'). As a result of this discussion based on the observations, it was determined that the degree of expansion, represented by $\alpha_{T}$ (or $\rho_{v \_g a s}$ ), is individual for each zone, in order to include the effect of geometric position in predicting the 'global' expansion of coating-thickness. This approach leads the derived equations to matrix algebra, as follows: 


$$
\left\{\alpha_{T, z}\right\}=\left\{\begin{array}{c}
\alpha_{T, z, 1} \\
\alpha_{T, z, 2} \\
\vdots \\
\alpha_{T, z, 8}
\end{array}\right\}=\frac{1}{\Delta T}\left\{\begin{array}{c}
\ln \left(1+\frac{d \ell_{z, 1}\left(T_{j}\right)}{\ell_{z, 1}\left(T_{0}\right)}\right) \\
\ln \left(1+\frac{d \ell_{z, 2}\left(T_{j}\right)}{\ell_{z, 2}\left(T_{0}\right)}\right) \\
\vdots \\
\ln \left(1+\frac{d \ell_{z, 8}\left(T_{j}\right)}{\ell_{z, 8}\left(T_{0}\right)}\right)
\end{array}\right\}
$$

where

$$
\begin{aligned}
& \left\{d \ell_{z}\right\}=\left\{\begin{array}{c}
d \ell_{z, 1} \\
d \ell_{z, 2} \\
\vdots \\
d \ell_{z, 8}
\end{array}\right\}=\frac{1}{2 \gamma}\left\{\begin{array}{c}
\sqrt{\left(\ell_{x, 1}\left(T_{j-1}\right)+\gamma \ell_{z, 1}\left(T_{j-1}\right)\right)^{2}+4 \gamma d V_{\text {enve }, 1}\left(T_{j}\right)} \\
-\left(\ell_{x, 1}\left(T_{j-1}\right)+\gamma \ell_{z, 1}\left(T_{j-1}\right)\right) \\
\sqrt{\left(\ell_{x, 2}\left(T_{j-1}\right)+\gamma \ell_{z, 2}\left(T_{j-1}\right)\right)^{2}+4 \gamma d V_{\text {enve }, 2}\left(T_{j}\right)} \\
-\left(\ell_{x, 2}\left(T_{j-1}\right)+\gamma \ell_{z, 2}\left(T_{j-1}\right)\right) \\
\vdots \\
\sqrt{\left(\ell_{x, 8}\left(T_{j-1}\right)+\gamma \ell_{z, 8}\left(T_{j-1}\right)\right)^{2}+4 \gamma d V_{\text {enve, }}\left(T_{j}\right)} \\
-\left(\ell_{x, 8}\left(T_{j-1}\right)+\gamma \ell_{z, 8}\left(T_{j-1}\right)\right)
\end{array}\right\} \\
& \left\{V_{\text {enve }}\right\}=\left\{\begin{array}{c}
V_{\text {enve, } 1} \\
V_{\text {enve, } 2} \\
\vdots \\
V_{\text {enve, } 8}
\end{array}\right\}=\left\{\begin{array}{c}
\frac{\beta_{T G A}\left(T_{j}\right) m_{e}}{\rho_{p_{-} \text {solid }}}+\sum_{i=1}^{j} \frac{\left(\beta_{T G A}\left(T_{i}\right)-\beta_{T G A}\left(T_{i-1}\right)\right) m_{e}}{\rho_{v_{-} g a s, 1}} \\
\frac{\beta_{T G A}\left(T_{j}\right) m_{e}}{\rho_{p_{-} \text {solid }}}+\sum_{i=1}^{j} \frac{\left(\beta_{T G A}\left(T_{i}\right)-\beta_{T G A}\left(T_{i-1}\right)\right) m_{e}}{\rho_{v_{-} g a s, 2}} \\
\vdots \\
\frac{\beta_{T G A}\left(T_{j}\right) m_{e}}{\rho_{p_{-} \text {solid }}}+\sum_{i=1}^{j} \frac{\left(\beta_{T G A}\left(T_{i}\right)-\beta_{T G A}\left(T_{i-1}\right)\right) m_{e}}{\rho_{v_{-} g a s, 8}}
\end{array}\right\} \\
& \left\{\rho_{v_{-} \text {gas }}\right\}=\left\{\begin{array}{c}
\rho_{v_{-} \text {gas }, 1} \\
\rho_{v_{-} \text {gas }, 2} \\
\vdots \\
\rho_{v_{-} \text {gas }, 8}
\end{array}\right\},\left\{\Phi_{\max }\right\}=\left\{\begin{array}{c}
\Phi_{\max , 1} \\
\Phi_{\max , 2} \\
\vdots \\
\Phi_{\max , 8}
\end{array}\right\}=\left\{\begin{array}{c}
0.865 \\
0.894 \\
\vdots \\
0.930
\end{array}\right\}
\end{aligned}
$$

The matrix $\left\{\alpha_{T}\right\}$ was determined through the comparison between numerical predictions and experimental measurements in this work. In relation to its determination, it was identified from several sensitivity studies that $\alpha_{T}$ affects both the histories of substrate temperature $\left(T_{s}(\mathrm{t})\right)$ and coating-thickness expansion $\left(\ell_{\mathrm{z}}(\mathrm{t})\right)$. An applicable matrix to the inorganic intumescent coating was therefore determined when concurrently creating two lines of best-fit, as shown in Figure 9(a), in terms of:

- The rate of the substrate temperature increase in the initial transient state ( $1^{\text {st }}$ stage);

- The level of the substrate temperature in the short plateau state $\left(2^{\text {nd }}\right.$ stage);

- The rate of the coating's thickness expansion over time $\left(d \ell_{\mathrm{z}}(\mathrm{t}) / d t\right)$. 
In the course of this process, to effectively define the group of unknown values, matrix $\left\{\alpha_{T}\right\}$ (or $\left\{\rho_{v_{\_} g a s}\right\}$ ), $\rho_{v_{-} \text {gas }}$ was assumed as being a linear function of the observed values of $\Phi_{\max }$, as shown in Figure 9(b).

Figure 10 shows the derived result of the matrix $\left\{\alpha_{T}\right\}$, which was assigned to FEA models to simulate the volume expansion of the intumescent coating at elevated temperatures. It is noted that the degree of expansion of the inorganic intumescent coating (matrix $\left\{\alpha_{T}\right\}$ ) was determined under the conditions of the coatings' dry film thickness of $3 \mathrm{~mm}$ (DFT) and the thermal load of $50 \mathrm{~kW} / \mathrm{m}^{2}\left(\dot{q}_{i r r}^{\prime \prime}\right)$. Based on the proposed sequence and the determined degrees of the multi-layers' expansions over temperature, the zones would systematically expand depending on their individual temperatures during cone testing, as illustrated in Figure 8(b) ('expanding state'), due to the temperature distribution along the expanding coating-thickness.

\section{Effective thermal conductivity}

Simultaneous to the 'external' volume expansion of the coating at elevated temperatures, its 'internal' body becomes porous. Its ability to transfer heat, which is represented by effective thermal conductivity ( $k_{\text {eff }}$ ), therefore varies in the course of intumescence which relies on temperature. In other words, once relationships amongst porosity $(\Phi), k_{\text {eff, }}$ and element temperature $\left(T_{e}\right)$ are defined, this dynamic phenomenon can be numerically modelled.

The relation between $T_{e}$ and $\Phi$ was derived from the proposed sequence of mass and volume changes. The relationship between $\Phi$ and $k_{\text {eff }}$ was thoroughly examined in the

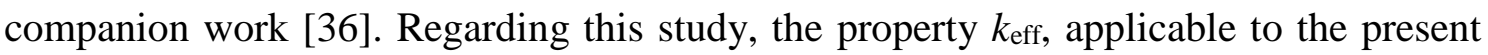
case, was determined based on the principle specialised for the mechanism of heat transfer in porous media. Use of this theory required considerations of heat transmissions through solid and void phases via conduction, convection, and radiation, as illustrated in Figure 11(a). This combined heat transfer mechanism depends on several factors, such as porosity, size and shape of pores, external thermal load, volume ratio of cell-strut to -wall, principal heat flow direction, and orientation and connectivity of local paths of conduction; the terms are described in Figure 11(b). Adequate methodology and assumptions therefore need to be established for engineering applications. In the companion study:

(i) a topological analysis was performed on the structural characteristics of the fully expanded coating-residue. Regarding the necessity of this sub-analysis, the internal morphology of the inorganic intumescent coating is constructed in the course of the rapid outward migration of the water vapours, released from endothermic decomposition reactions. Its structure is composed of both open and closed pores with irregular size. From a practical point of view, a process of definition of a representative elemental cell (REC) was therefore required for modelling its sporadic morphology. SEM images of the porous medium sampled from EF tests, as shown in Figure 2(d), were used in the topological analysis, which produced probability distributions of pore-size and -volume. As a result, the REC, applicable to the present case, was defined as a $200 \mu \mathrm{m}$-sized pore filled with semi-transparent media; 
(ii) a prototype single-enclosure model was initially developed using the FEA tool with user subroutines for calibration of the numerical modelling. A mechanism of radiation transfer through the unit-REC filled with translucent media was formulated based on the extended net-radiation method [37], and applied to the FEA simulations. The prototype model was then extended to multi-cellular models, to assess the thermal insulation performance of the porous medium (i.e.,

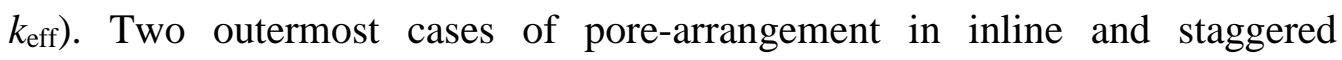
configurations were considered, in order to define the upper and lower bounds of $k_{\text {eff }}$ at a designated porosity, as illustrated in Figure 12. The simulations produced the histories of the top- and bottom-surface temperatures of the porous structures $\left(T_{\text {top }}(t)\right.$ and $\left.T_{b t m}(t)\right)$;

(iii) from the data of FEA simulations, $k_{\text {eff }}$ was derived based on the principle of the steady-state guarded hot-plate method, as follows:

$$
k_{\text {eff }}=\frac{\dot{q}_{\text {net_in }}^{\prime \prime} \ell_{z}}{T_{\text {top_steady }}-T_{\text {btm_steady }}}=k_{\text {c_solid }}+k_{\text {c_void }}+k_{\text {r_void }}
$$

where $\dot{q}_{\text {net_in }}^{\prime \prime}$ and $\ell_{z}$ refer to the external thermal load imposed on the exposed top surface of the coating and the thickness of the fully expanded coating, while $T_{\text {top_steady }}$ and $T_{b t m \_s t e a d y}$ denote $T_{\text {top }}(t)$ and $T_{b t m}(t)$ at a steady-state, respectively. In addition, the property $k_{\text {eff }}$ was defined as being composed of effective solid conductivity ( $k_{\text {c_solid }_{1}}$ ), effective void conductivity ( $k_{\mathrm{c}_{-} \text {void }}$ ), and effective 'radiative' conductivity ( $\left.k_{r_{-} \text {void }}\right)$ in the companion work, in order to quantify their individual contributions to the overall mechanism of heat transfer.

From the multi-cellular FEA simulations, the $\Phi$ - $k_{\text {eff }}$ relationship was determined. Figure 13 shows the numerical predictions (dotted lines with symbols, titled 'inline' and 'staggered'), superimposed on the data obtained from existing generic models. As a result, $T_{e}{ }^{-} k_{\text {eff }}$ profiles in upper and lower bounds were derived in association with the defined $T_{e^{-}}$ $\Phi$ and $\Phi-k_{\text {eff }}$ relations, as demonstrated in Figures 14(a) and (b). These profiles are assigned to the multi-layer FEA modelling being mainly discussed in this paper.

\section{Numerical modelling}

The sequence proposed for a single element ( $k$ th layer) was applied to each of the multilayered elements by employing ABAQUS/Standard. To calibrate this FEA approach, a one-dimensional (1-D) multi-layer model was initially designed in z-direction, as illustrated in Figure 15(a). It includes the findings from the five sub-topics discussed: Thermal boundaries; Nonlinear distribution of temperature along coating-thickness; Intumescence coupled with heat absorption and mass loss; Inconsistent degrees of expansion along coating-thickness; and Effective thermal conductivity. A four-noded plane stress element (i.e., CPS4T), developed to carry out coupled temperaturedisplacement analysis [38], was used. Nonlinear thermo-physical properties of the coating, obtained from the bench-scale tests (Figures 2(b), 2(c), 10, and 14), were assigned to the model, while the properties of the other materials used are listed in Table 1. It is noted that the more detailed temperature distribution along the expanding coating-thickness the 
more sophisticated prediction of the coating's intumescence. In order for a detailed temperature gradient to be predicted, the number of the isothermal elemental layers was determined as 150 units, which resulted in each of the virgin elements having infinitesimal thicknesses of $13.3 \mu \mathrm{m}, 20.0 \mu \mathrm{m}$, and $26.7 \mu \mathrm{m}$ at DFT=2 mm, $3 \mathrm{~mm}$, and 4 mm, respectively.

In order for a more sophisticated behaviour to be predicted, the 1-D model was extended to two dimensions; the selection of the 2-D model, rather than 3-D one, was previously explained in the section of thermal boundaries. This extended model was designed as a half-width plane which exposes its horizontal top and vertical side edges to the heat source and surroundings, as shown in Figure 15(b). The unit-element's thicknesses, established in the 1-D simulation, were still used while its width was determined as $1 \mathrm{~mm}$. Since the coating's major behaviours, such as heat transfer and volume expansion, occur in $\mathrm{z}$-direction, the $\mathrm{x}$-directional dimension 'width' has minor effects on the numerical results and $1 \mathrm{~mm}$-width element is therefore sufficiently small for achieving numerical accuracy. In terms of computational efficiency, the 2-D model has 8,400 elements with 25,251 nodes and consumes the average CPU time of 19,784 seconds for a single simulating process. Hence, it can be deduced that this approach to the number and size of elements meets the requirement of numerical efficiency, as well as accuracy; the accuracy will be demonstrated in the section of verification.

From the simulations using the 2-D multi-layer FEA model, two sets of profiles were mainly predicted: Histories of (i) substrate temperature and (ii) coating-thickness expansion $\left(T_{s}(\mathrm{t})\right.$ and $\left.\ell_{\mathrm{z}}(\mathrm{t})\right)$. These results were obtained using the method of transient fully coupled thermal-stress analysis, provided by the FEA software. This method requires consideration of changes in time, as well as in temperature and space. The Euler differential equation of the boundary value problem on a solution-domain $\left(\Omega^{\mathrm{e}}\right)$ is solved adopting the calculus of variations based on the principle of minimum potential energy (П) [39]. It is then reformulated using trial solutions (shape functions) in the form of algebraic matrix, as follows:

$$
\Pi=[\delta \theta]\left[[C]\{\dot{\theta}\}+\frac{1}{2}[K]\{\theta\}-\left\{Q_{n e t}\right\}\right]=0
$$

$$
\text { where } \begin{aligned}
{[C]=\int_{\Omega^{e}} } & {[N]^{T}[N] \rho c d \Omega^{e},[K]=\int_{\Omega^{e}}[B]^{T}[D][B] d \Omega^{e},\left\{Q_{n e t}\right\}=\int_{\Gamma^{e}}[N]^{T} Q_{n e t} d \Gamma^{e} } \\
{[\mathrm{C}] } & =\text { thermal capacitance matrix } \\
\{\theta\} & =\text { nodal temperature matrix } \\
{[\mathrm{K}] } & =\text { conduction (stiffness) matrix } \\
\left\{Q_{\mathrm{net}}\right\} & =\text { matrix of the rate of net heat transferred on } \Gamma^{\mathrm{e}} . \\
{[\mathrm{N}] } & =\text { shape (interpolation) function matrix } \\
{[\mathrm{B}] } & =\text { displacement differentiation matrix } \\
{[\mathrm{D}] } & =\text { material property matrix } \\
\Omega^{\mathrm{e}} & =\text { elemental solution domain } \\
\Gamma^{\mathrm{e}} & =\text { boundary of solution domain } \\
\rho & =\text { density } \\
C & =\text { specific heat }
\end{aligned}
$$

For time-stepping solution in transient FEA, the backward Euler method (modified Crank-Nicholson method, $\xi=1$ ) is used based on the Finite Difference (FD) technique [39- 
40]. The rate of temperature increment with respect to time can be equated using linear interpolation, as follows:

$$
\{\dot{\theta}\}=\frac{\{\theta(t+d t)\}-\{\theta(t)\}}{d t}=\frac{\theta_{i+1}-\theta_{i}}{d t},\{\theta\}=\theta_{i+1}
$$

where $\xi$ and $i$ refer to a weighting factor that is in the range of 0 to 1 , and the iteration of the time-stepping process, respectively. Once this concept of iteration is applied to equation (10), it becomes:

$$
\begin{array}{cc}
\left(\frac{C}{d t}+\xi K\right) \theta_{i+1} & =\left[\frac{C}{d t}-(1-\xi) K\right] \theta_{i}+Q_{\text {net }} \\
& C \dot{\theta}_{i+1}+K \theta_{i+1}=Q_{\text {net }}
\end{array}
$$

This FD algorithm-based formula is applied for the calculation of increases in element temperature $\left(T_{e}\right)$ at each instant of time, from an initial condition at $t=0$ (or $i=0$ ). This process is coupled with the FE method-based predictions of temperature distributions through the multi-layer and volume expansions.

\section{Results and discussion}

\section{Verification}

The 2-D FEA multi-layer modelling, based on the proposed sequence of intumescence, was verified by the experimental data, gained from the cone calorimeter test. Figures 1619 demonstrate the histories of (i) temperature of the underlying steel substrate $\left(T_{s}(\mathrm{t})\right)$ and (ii) thickness of the intumescent coating $\left(\ell_{\mathrm{z}}(\mathrm{t})\right)$, obtained from the FEA predictions and physical measurements under the different conditions of DFT=2, 3, and $4 \mathrm{~mm}$ and $\dot{q}_{i r r}^{\prime \prime}=35,50$, and $65 \mathrm{~kW} / \mathrm{m}^{2}$; Figures 16(a)-19(a) show the overall data of $T_{\mathrm{s}}(\mathrm{t})$ and $\ell_{\mathrm{z}}(\mathrm{t})$, while Figures 16(b)-19(b) demonstrate close-up views of their initial stages. The cross symbol indicates the test results, whilst the continuous solid and chain thin lines refer to the numerical results gained when respectively adopting the upper and lower limits of $k_{e f f}$, as shown in Figure 14.

Overall, it can be observed that the FEA model produced the $T_{s}(\mathrm{t})$ predictions in agreement with experimental data, from the $1^{\text {st }}$ stage (as defined in Figures 2(e) and (f)), through the $2^{\text {nd }}$ and $3^{\text {rd }}$ stages, to the $4^{\text {th }}$ stage. With respect to $\ell_{\mathrm{z}}(\mathrm{t})$, the numerical predictions also agreed with the measurements from transient to steady states with consistent accuracy. It is noted that although the degree of expansion (i.e., matrix $\left\{\alpha_{T}\right\}$ ) was determined under the 'single' condition of DFT=3 mm and $\dot{q}_{i r r}^{\prime \prime}=50 \mathrm{~kW} / \mathrm{m}^{2}$, it led to accurate predictions even under other different conditions of DFT and $\dot{q}_{i r r}^{\prime \prime}$. This indicates that the determined matrix $\left\{\alpha_{T}\right\}$ can be considered to be one of thermo-physical properties of the inorganic intumescent coating.

\section{Mechanism of heat transfer impediment}


Figure 20(a) shows the temperature-time profiles of the steel substrate $\left(T_{s}(\mathrm{t})\right)$ and the coating's elemental layers, affiliated to the individual zones, at DFT $=3 \mathrm{~mm}$ and $\dot{q}_{i r r}^{\prime \prime}=50$ $\mathrm{kW} / \mathrm{m}^{2}$. It demonstrates the impediment to the progress of transient heat transfer, from the top layer directly exposed to the heater and surroundings (in Zone 1) through the coating-body to the underlying steel plate, in association with its thermo-kinetic characteristics and the formation of porous structure in its internal volume. The hatched grey region denotes the approximate range of temperature (about $50{ }^{\circ} \mathrm{C} 120^{\circ} \mathrm{C}$ ) in which both the initial endothermic water vaporisation with dehydration, as shown in Figure 2(b), and the reduction of effective thermal conductivity, $k_{\text {eff, }}$ as illustrated in Figure 14, mainly occur. The grid grey and blank (white) areas refer to the approximate temperature ranges where the continual water vaporisation with dehydration (about $120^{\circ} \mathrm{C} \sim 230^{\circ} \mathrm{C}$ ) and endothermic reactions with dehydroxylation (about $230{ }^{\circ} \mathrm{C} \sim$ ) gently take place, respectively. It is noted that these regions are not discrete but partially overlapped.

Specifically, it was found that there existed a rapid increase in the temperature of the coating's top layer (in Zone 1 ) in the initial period of time ( 1 minute). During this stage, the layer had absorbed heat which was consumed for the endothermic reactions (Figure 2(b)). These led to (i) the release and migration of water molecules (Figure 2(a)), (ii) the generation of microscopic pores (Figure 2(d)), (iii) the reduction of $k_{\text {eff }}$ (Figure 14), and (iv) the increase in the element's thickness (Figure 2(f)). These sequential responses resulted in the enhancement of thermal insulation performance of the top layer, and thus allowed only a small portion of the absorbed heat to transfer down to the lower layer at each time-increment. The heat which failed to be transferred downward induced the rapid increase in the top layer's temperature. Concurrently, the contemporary responses of the lower layer (affiliated to Zone 2) individually progressed, in accordance with the proposed sequence of intumescence. However, the increase in its temperature was impeded, as compared to that of the upper layer, due to the small amount of heat supplied from the upper layer. Hence, the temperature gaps between the upper and lower layers (e.g., $\Delta T_{1-2}, \Delta T_{2-3}, \cdots$ ) had considerably widened over time.

In addition to this aspect, it can be identified that the rate of the temperature rise of each of the layers had gradually reduced in the green and blue regions. This phenomenon is ascribable to the two facts: (i) Part of the heats, absorbed by the individual layers at each time-increment, was continually consumed for endothermic water vaporisations with dehydration and dehydroxylation; (ii) The quantity of heat loss from the top layer to the surroundings, via radiant emission, increased quickly with the fast growth of this layer's temperature. The radiant emission is the dominant mechanism of heat loss at elevated temperatures, and an increase in its quantity reduces in turn the amount of the net heat absorbed by the coating at each time-increment. Therefore, the rapid increase in radiant emission, represented by the coating's emissivity, also contributed to the heat transfer impediment. Consequently, the aspects discussed had detained fast temperature rises of the multi-layers, which had protected the underlying substrate from the external thermal load in order. 
Figure 20(b) shows the logarithmic thermal strain histories of the elemental layers at $\dot{q}_{i r r}^{\prime \prime}=50 \mathrm{~kW} / \mathrm{m}^{2}$ and DFT=3 $\mathrm{mm}$. The profiles indicate the individual development of intumescence of each of the isothermal layers, depending on their temperature and degree of expansion. The cross symbol refers to the experimental measurements, whilst the black dotted line denotes the prediction of 'global' thermal strain of the coating.

This figure demonstrates an ongoing interaction between thermal (heat transfer) and physical (volume expansion) behaviours, in association with Figure 20(a). At $t=5$ minutes in Figure 20(b), the elemental layers in from Zone 1 to 5 were fully expanded, indicating that these elements had already undergone both the reduction of $k_{\text {eff }}$ and the increase in length of conductive heat transfer path (i.e., $\ell_{z}$ in equation (5)). In the case of the layers in Zones 6, 7, and 8, the changes in $k_{\text {eff }}$ and $\ell_{z}$ were still in progress. At this instant of time in Figure 20(a), the layers in Zones 6, 7, and 8 still remained in the hatched grey area, indicating that the elements undergo the ongoing variations in $k_{\text {eff }}$ and $\ell_{z}$. It can be therefore concluded that the thermal volume-expansion of the coating was instrumental in promoting the impediment of heat transfer to the substrate, and this fire-retardant system functioned based on the combination of the thermal and physical behaviours.

\section{Conclusions}

This work aimed to investigate the interacting thermo-physical behaviour of an inorganictype intumescent system. Its behaviour was systematically analysed, from microscopic thermo-kinetic characteristics to macroscopic physics of heat transfer and thermal expansion. A series of sequential steps to determine the mass and volume changes of a unit element were designed. Subsequently, this temperature-dependent sequence was numerically simulated by a 2-D multi-layer model. It was developed based on the coupled temperature-displacement finite element analysis procedure, in association with benchscale tests utilising TGA, DSC, electric furnace, and cone calorimetry.

This modelling involved the following critical issues: (i) Variations in irradiance on the moving boundaries of the coating-sample; (ii) Heat losses from its exposed surfaces, via radiant emission and free convection; (iii) Temperature-dependent nonlinear heat capacity, including sensible and latent heats for water vaporisation with dehydration and dehydroxylation; (iv) Systematic temperature-dependent changes in mass, volume, and porosity; (v) Effective thermal conductivity, representing the heat transfer through its porous structure, via solid conduction, void conduction, and cavity radiation; and (vi) Distributions of temperature and degree of expansion, along the coating-thickness. The numerical predictions were verified by the experimental data. It showed consistent agreements under several conditions of external thermal load and specimen-thickness, which could not have been achieved unless the key issues were included in modelling.

It can be identified that this fire retardant coating provided effective insulation to the underlying substrate, due to the following main reasons: (i) The absorption of sensible and latent heats, consumed for water vaporisation with dehydration and dehydroxylation; (ii) The reduction of effective thermal conductivity; (iii) The increase in length of the path of conductive heat penetration; and (iv) The active heat loss via radiant emission on the coating's exposed surfaces. It can be therefore concluded that water-content, porosity, 
degree of expansion, and emissivity are closely related to the enhancement or optimisation of thermal insulation performance of this refractory system.

\section{Declaration of conflicting interests}

The authors declare that there is no conflict of interest.

\section{Funding}

This project is funded by Korean Ministry of Public Safety and Security through R\&D programme on Fire Safety and 119 Rescue Technology: development of personal protective equipment for accidentally high risk circumstances under extreme situations. 


\section{References}

1. SteelConstruction.info. Steel Insight 2 - Cost planning through design stages, www.steelconstruction.info/uploads/ftpin/Steel_Insight2/?pdfPath=Steel_Insight2\#/ $\underline{1 /}$ (2012, accessed 15 September 2016).

2. Bourbigot S, Duquesne S. Intumescence-based fire retardants. In: Wilkie CA, Morgan AB, Fire retardancy of polymeric materials. 2nd ed. New York: CRC Press, 2010, pp.129-162.

3. Vandersall HL. Intumescent coating systems, their development and chemistry. Journal of Fire and Flammability 1971; 2: 97-140.

4. Weil ED. Fire-protective and flame-retardant coatings - A State-of-the-Art review. Journal of Fire Sciences 2011; 29: 259-296.

5. Mariappan T. Recent developments of intumescent fire protection coatings for structural steel: A review. Journal of Fire Sciences 2016; 34(2): 120-163.

6. BS 476-15 (ISO 5660-1). Fire tests on building materials and structures - Part 15: Method for measuring the rate of heat release of products.

7. Schartel B, Bartholmai M, Hull TR. Some comments on the use of cone calorimeter data. Polymer Degradation and Stability 2005; 88: 540-547.

8. Schartel B, Hull TR. Development of fire-retarded materials - Interpretation of cone calorimeter data. Fire and Materials 2007; 31: 327-354.

9. Choi JY, Jang HM, Chun C. Thermal characteristics measurements of an inorganic intumescent coating system. In: International Conference Applications of Structural Fire Engineering, Prague, Czech Republic, 19-20 February 2009, pp.128-133.

10. Bulewicz EM, Pelc A, Koziowski R. Intumescent silicate-based materials: Mechanism of swelling in contact with fire. Fire and Materials 1985; 9(4): 171-175.

11. Pélégris C, Rivenet M, Traisnel M. Intumescent silicates: Synthesis, characterisation and fire protective effect. In: le Bras M, Bourbigot S, Duquesne S, Jama C, Wilkie CA, Fire Retardancy of Polymers: New Applications of Mineral Fillers. 1st ed. Royal Society of Chemistry, 2005, pp.68-78.

12. Clark KL, Shimizu AB, Suchsland KE, Moyer CB. Analytical modelling of intumescent coating thermal protection system in a JP-5 fuel fire environment. Report no. N74-29016, Aerotherm Corp., June 1974.

13. Cagliostro DE, Riccitiello SR. Intumescent coating modelling. Journal of Fire and Flammability 1975; 6: 205-221.

14. Anderson CE, Dziuk J, Mallow WA, Buckmaster J. Intumescent reaction mechanisms. Journal of Fire Sciences 1985; 3: 161-194.

15. Buckmaster J, Anderson CE, Nachman A. A model for intumescent paints. International Journal of Engineering Science 1986; 24(3): 263-276.

16. Shih YC, Cheung FB, Koo JH. Theoretical modelling of intumescent fire-retardant materials. Journal of Fire Sciences 1998; 16: 46-71.

17. Blasi CD, Branca C. Mathematical model for the nonsteady decomposition of intumescent coatings. AIChE Journal 2001; 47(10): 2359-2370.

18. Blasi C.D. Modelling the effects of high radiative heat fluxes on intumescent material decomposition. Journal of Analytical and Applied Pyrolysis 2004; 71: 721-737. 
19. Bhargava A, Griffin GJ. A two dimensional model of heat transfer across a fire retardant epoxy coating subjected to an impinging flame. Journal of Fire Sciences 1999; 17(3): 188-208.

20. Bhargava A, Griffin GJ. A model of heat transfer across an epoxy based fire retardant layer undergoing sublimation, intumescence and degradation. Developments in chemical engineering and mineral processing 2000; 8: 75-91.

21. Griffin GJ. The modelling of heat transfer across intumescent polymer coatings. Journal of Fire Sciences 2010; 28(3): 249-277.

22. Staggs JEJ. Thermal conductivity estimates of intumescent chars by direct numerical simulation. Fire Safety Journal 2010; 45: 228-237.

23. Staggs JEJ, Crewe RJ, Butler R. A theoretical and experimental investigation of intumescent behaviour in protective coatings for structural steel. Chemical Engineering Science 2012; 71: 239-251.

24. Mamleev VSh, Bekturov EA, Gibov KM. Dynamics of intumescence of fireretardant polymeric materials. Journal of Applied Polymer Science 1988; 70: 15231542.

25. Wang YC, Göransson U, Holmstedt G, Omrane A. A model for prediction of temperature in steel structure protected by intumescent coating, based on tests in the cone calorimeter. In: International Symposium Fire Safety Science, Beijing, China, 18-23 September 2005, pp.235-246.

26. Yuan JF, Wang YC. Efficient modelling of temperatures in steel plates protected by intumescent coating in fire. In: Hull TR, Kandola BK, Fire Retardancy of Polymers: New Strategies and Mechanisms. 1st ed. Royal Society of Chemistry, 2009, pp.225239.

27. Zhang Y, Wang YC, Bailey CG, Taylor AP. Global modelling of fire protection performance of intumescent coating under different cone calorimeter heating conditions. Fire Safety Journal 2012; 50: 51-62.

28. Russell HW. Principles of heat flow in porous insulators. Journal of American Ceramic Society 1935; 18 (1-12): 1-5.

29. Staggs JEJ. Heat and mass transport in developing chars. Polymer Degradation and Stability 2003; 82: 297-307.

30. Staggs JEJ. Numerical characterisation of the thermal performance of static porous insulation layers on steel substrates in furnace tests. Journal of Fire Sciences 2011; 29: 177-192.

31. Bakker K. Using the finite element method to compute the influence of complex porosity and inclusion structures on the thermal and electrical conductivity. International Journal of Heat and Mass Transfer 1997; 40(15): 3503-3511.

32. Druma AM, Alam MK, Druma C. Analysis of thermal conduction in carbon foams. International Journal of Thermal Sciences 2004; 43: 689-695.

33. Chapra SC, Canale RP. Numerical methods for engineers. 6th ed. New York: McGraw-Hill International Edition, 2010.

34. Kang SW, Choi SK, Choi JY. Numerical prediction on interacting thermal-structural behaviour of inorganic intumescent coating. In: International Conference and Exhibition on Fire Science and Engineering (Interflam), Nr Windsor, UK, 4-6 July 
2016, pp.213-224.

35. Kang SW, Choi SK, Choi JY. View factor in cone calorimeter testing. International Journal of Heat and Mass Transfer 2016; 93: 217-227.

36. Kang SW, Numerical prediction of interacting thermal-structural behaviour of inorganic intumescent system: Part 1 - Heat transfer through porous structures (Chapter 5). In: Thermal-structural behaviour of inorganic intumescent system. $\mathrm{PhD}$ Thesis, Ulster University, 2016, pp.100-161.

37. Siegel R, Howell JR. Thermal radiation heat transfer. 4th ed. London: Taylor \& Francis, 2002.

38. Abaqus analysis user's manual. Fully coupled thermal-stress analysis (6.5.3). In: Abaqus 6.13 Documentation.

39. Cook RD, Malkus DS, Plesha ME, and Witt RJ. Heat transfer and selected fluid problems. In: Concepts and applications of Finite Element Analysis. 4th ed. the United State: John Wiley \& Sons, Inc., 2002, pp.454.

40. Dassault Systèmes Simulia. Heat transfer and thermal-stress analysis with Abaqus, 2010.

\section{Author biographies}

Sungwook Kang has recently joined Korea Conformity Laboratories, after completing his PhD in fire safety at Ulster University. He received a BSc from Korea University in Architectural Engineering in 2008 and his MSc in Structural and Fire Safety Engineering from University of Edinburgh in 2009. His research interests include bench-scaled fire testing and numerical modelling to understand thermal \& mechanical behaviours of intumescent fire resistive materials.

Sengkwan Choi is Reader in School of the Built Environment at Ulster University, UK. He obtained BSc of Civil Eng. from Inha University in South Korea and MSc of Structural Eng. from UMIST. After a short period in practice, he completed his doctorate in a field of structural fire safety in 2005 at University of Sheffield. Prior to take up an appointment of lectureship at Ulster University, he worked for three years as a senior researcher of structural fire engineering at Korean Institute of Construction Technology. He has maintained a close working relationship with industries such as steel construction, fire protection and structural consultancy. His research work involves various aspects of fire safety engineering, from the experiments on fire related tests through to numerical analyses, conceptual applications and the development of new design methodologies. He has published over 40 papers in the research programme on fire protection engineering.

JoungYoon Choi has been working as a principal researcher at Dept. of Built Environments, Korea Conformity Laboratories since 2005. Before joining KCL, he did his PhD and MSc degrees at School of Chemistry, University of Bristol in the UK and BEng at Dept. of Polymer Science and Engineering in Pusan National University in South Korea. He was a secretary of ISO/TC219 (Floor Coverings) and a proposer of a newly 
developing standard about wood plastic composites at ISO/TC61 (Plastics) / SC11 (products). He has published 10 peer reviewed research papers and one co-authored book at the related field. 


\section{FIGURE}

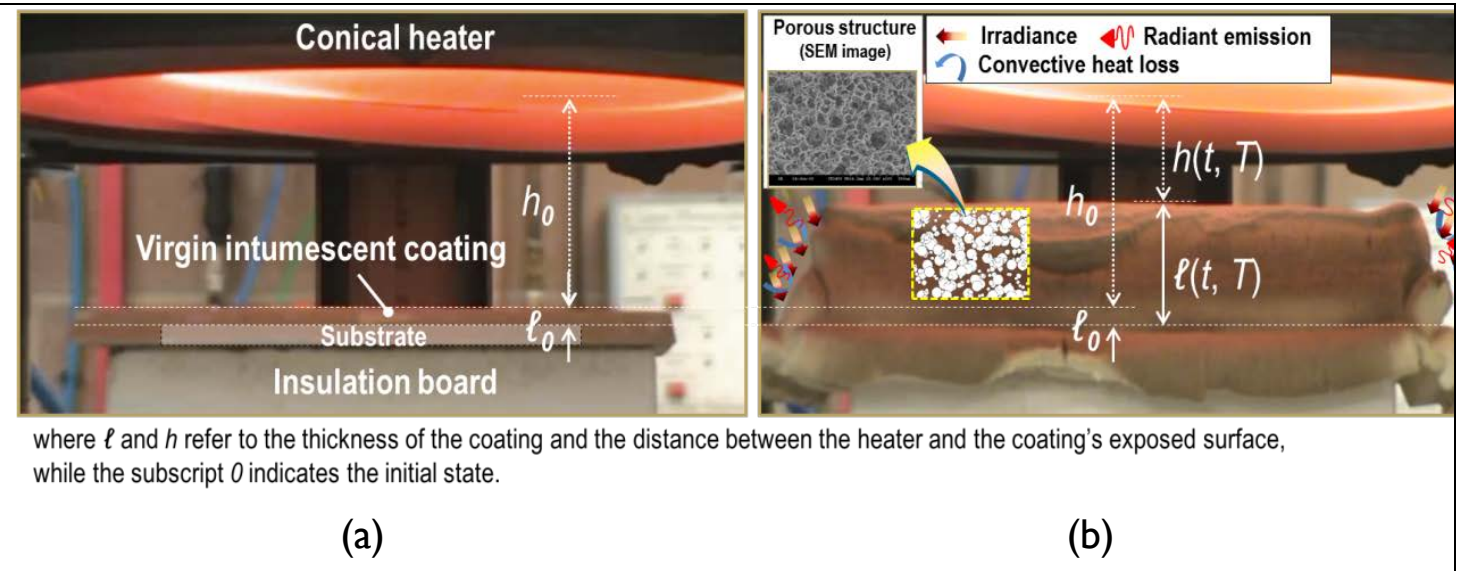

Figure I. Inorganic-based intumescent coating, tested with cone calorimetry: In (a) virgin state and (b) fully-expanded state. 


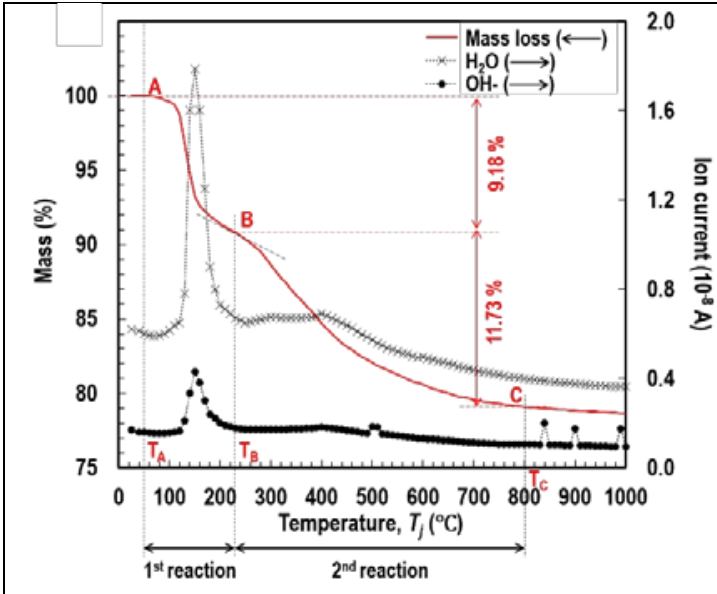

(a)

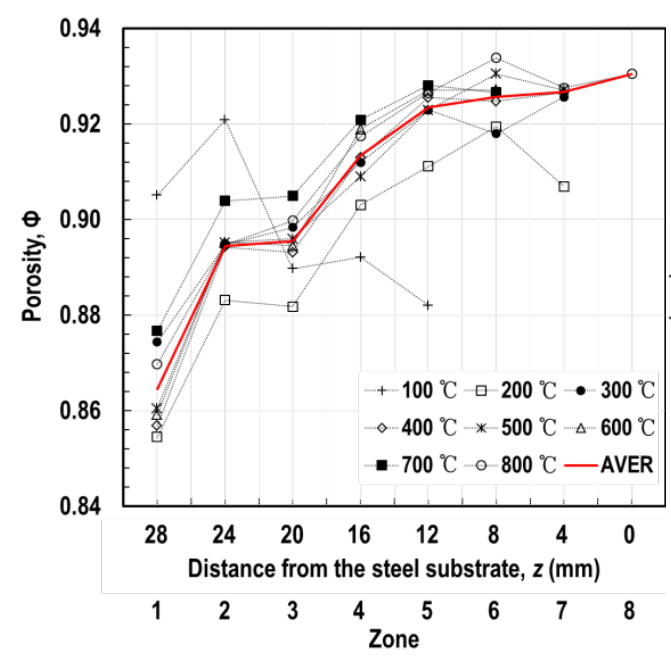

(c)

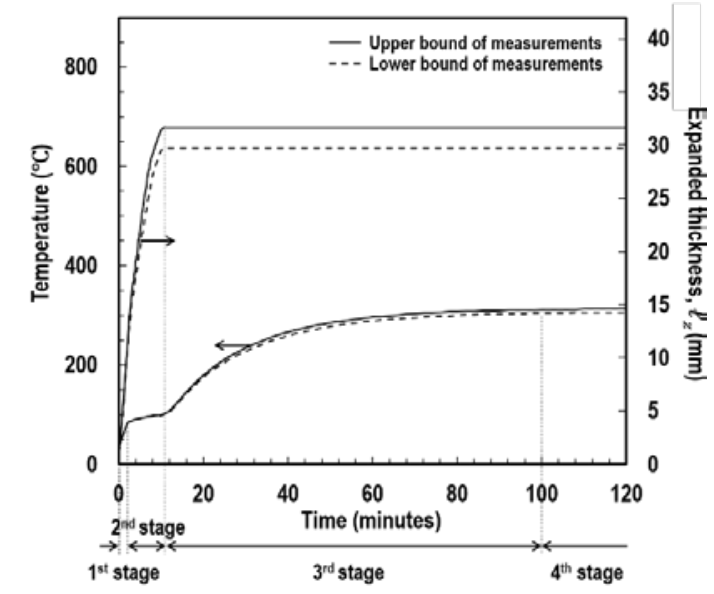

(e)

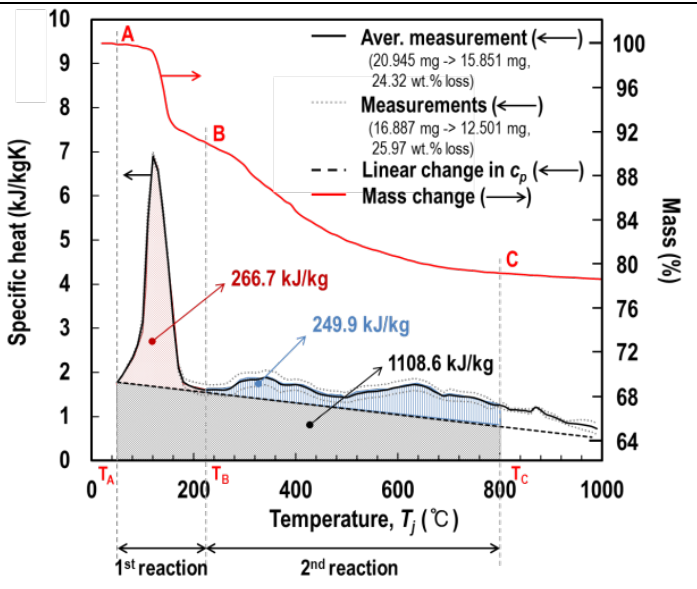

(b)

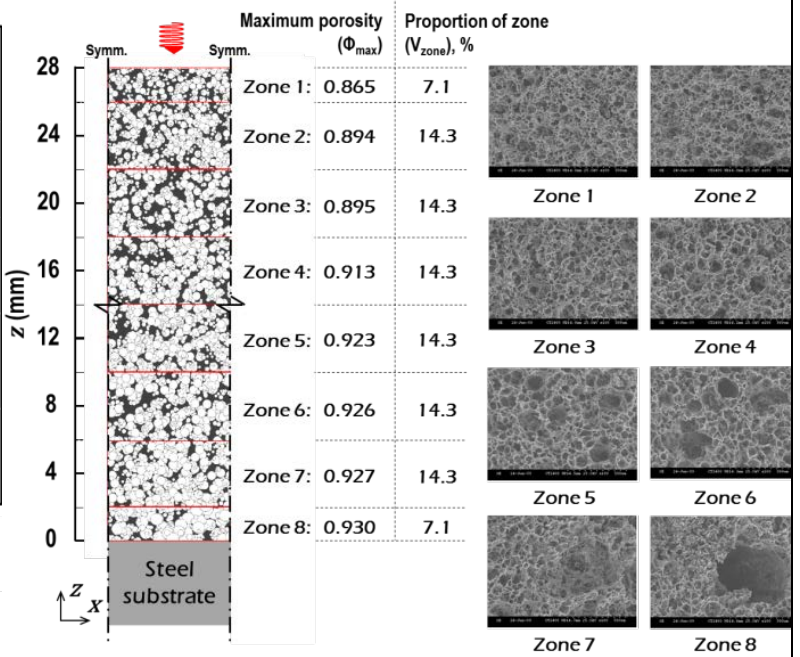

(d)

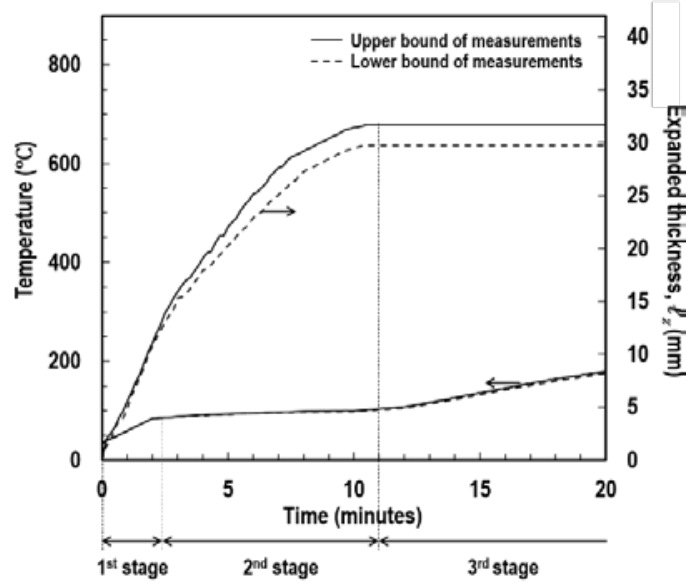

(f)

Figure 2. Experimental results: (a) temperature-dependent mass loss (TGA-MS), (b) temperature-dependent specific heat (DSC), (c) porosity distribution along thickness of fully expanded coating (EF), (d) schematic of porosity distribution (EF), (e) overall histories of substrate temperature and coating thickness at $\dot{q}_{i r r}^{\prime \prime}=50$ $\mathrm{kW} / \mathrm{m}^{2}$ and dry-film thickness $=3 \mathrm{~mm}$, and $(f)$ their initial histories $(\mathrm{CC})$. 


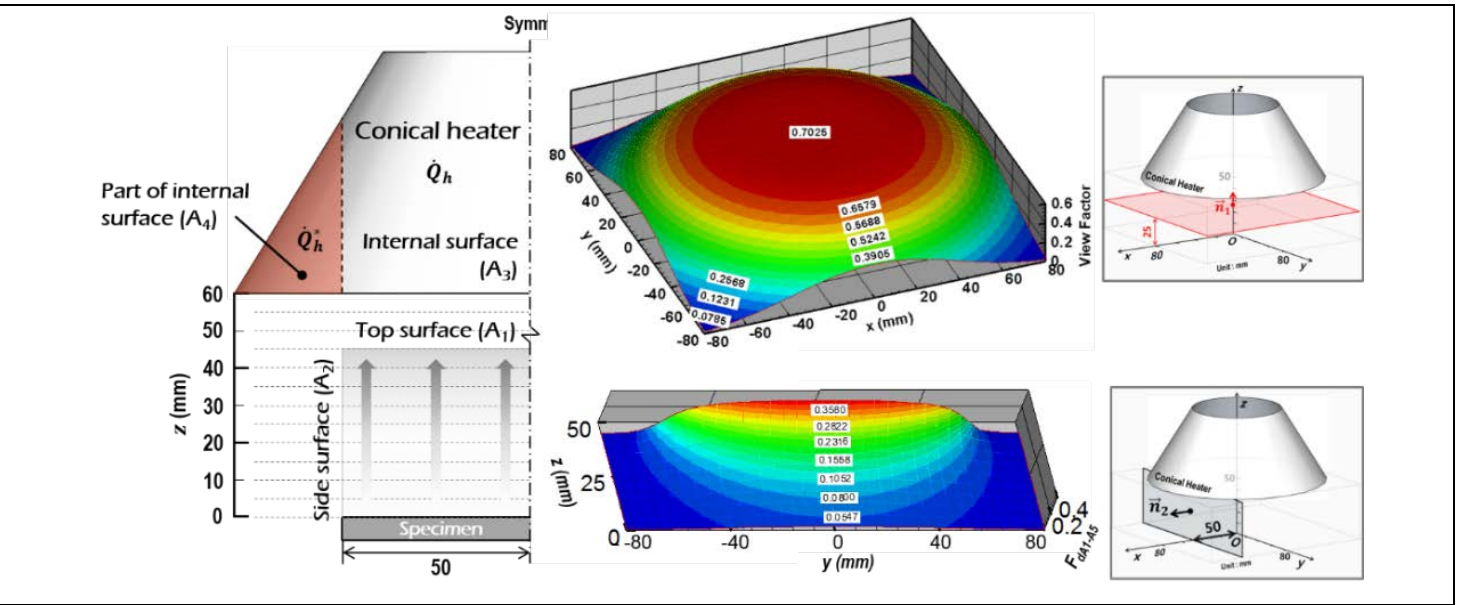

Figure 3. Irradiances on moving boundaries of intumescent specimen tested with cone calorimetry.

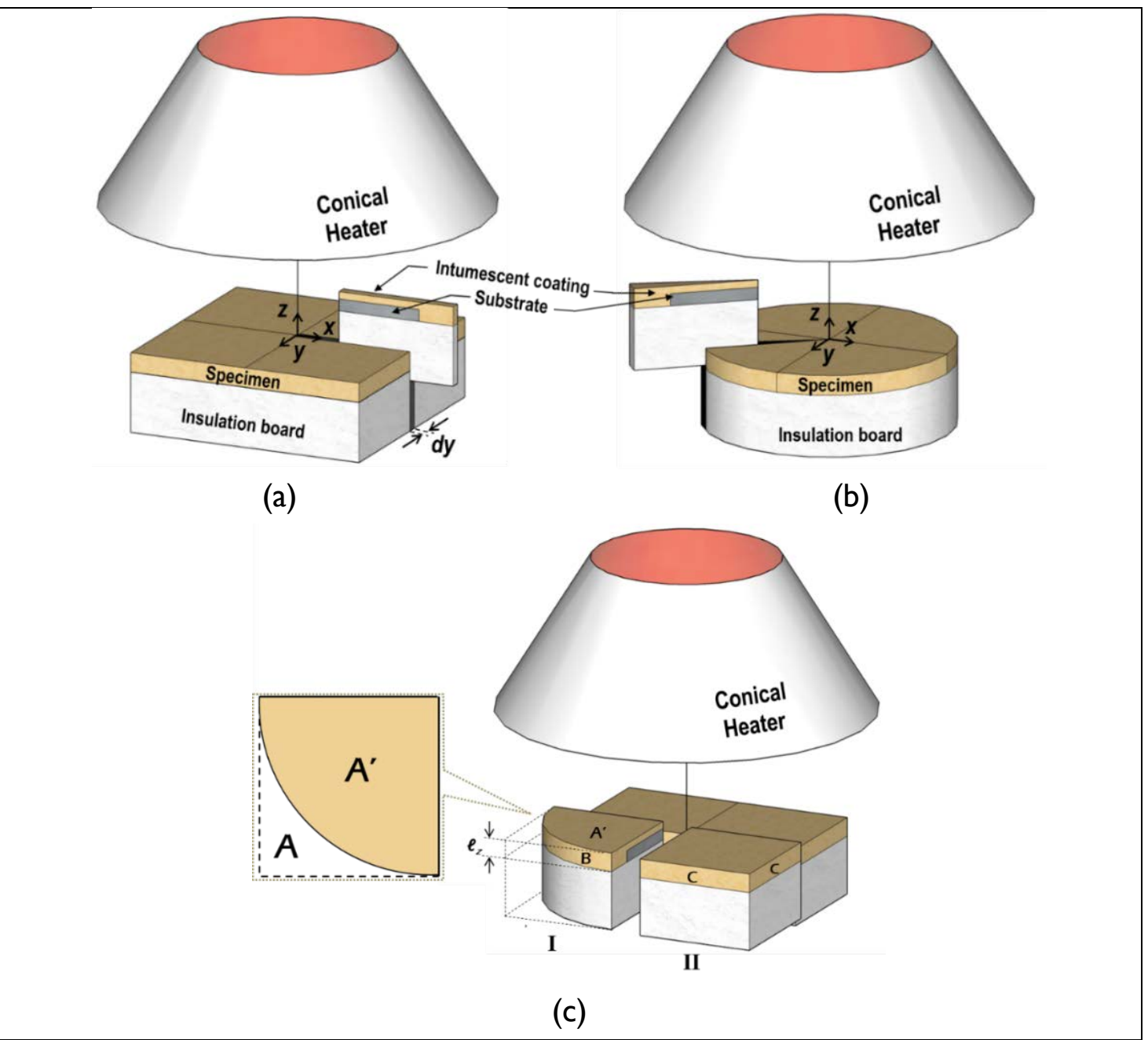

Figure 4. Consideration on two- and three-dimensional modelling schemes: (a) 2-D plane, (b) 2-D wedge, (c) 3-D quarter wedge (I) and 3-D quarter models (II). 


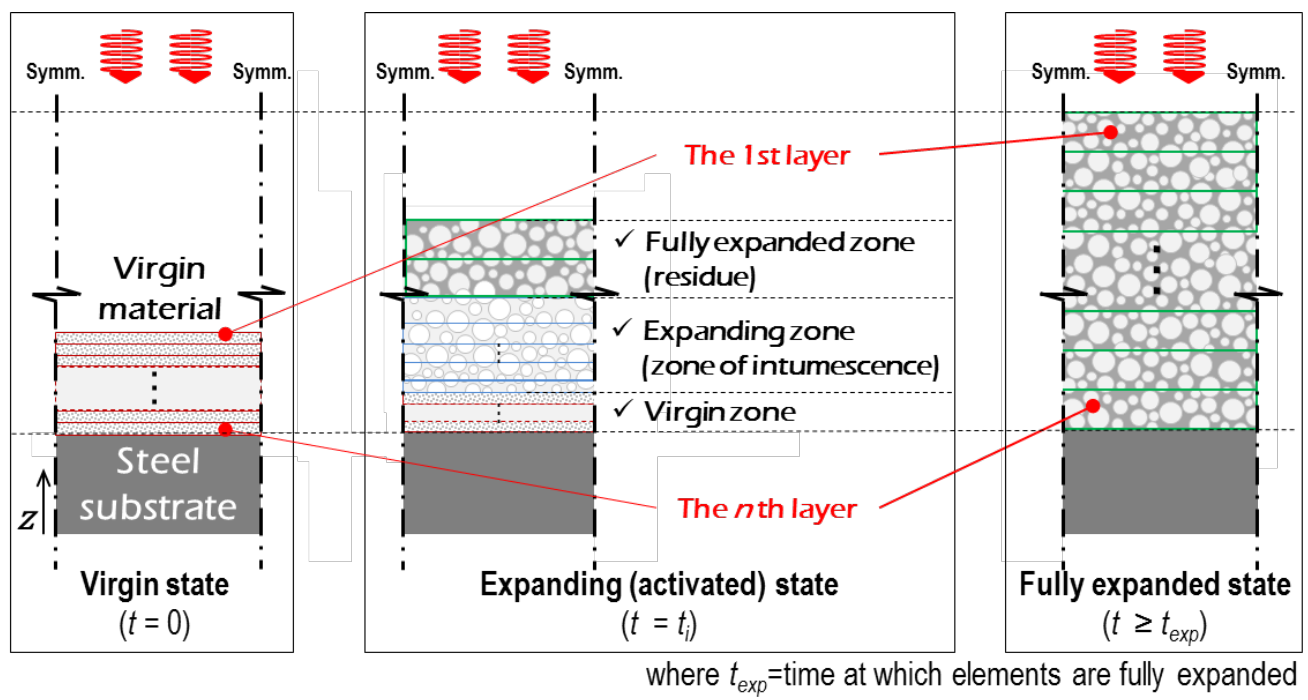

Figure 5. Scheme of FEA multilayer modelling.

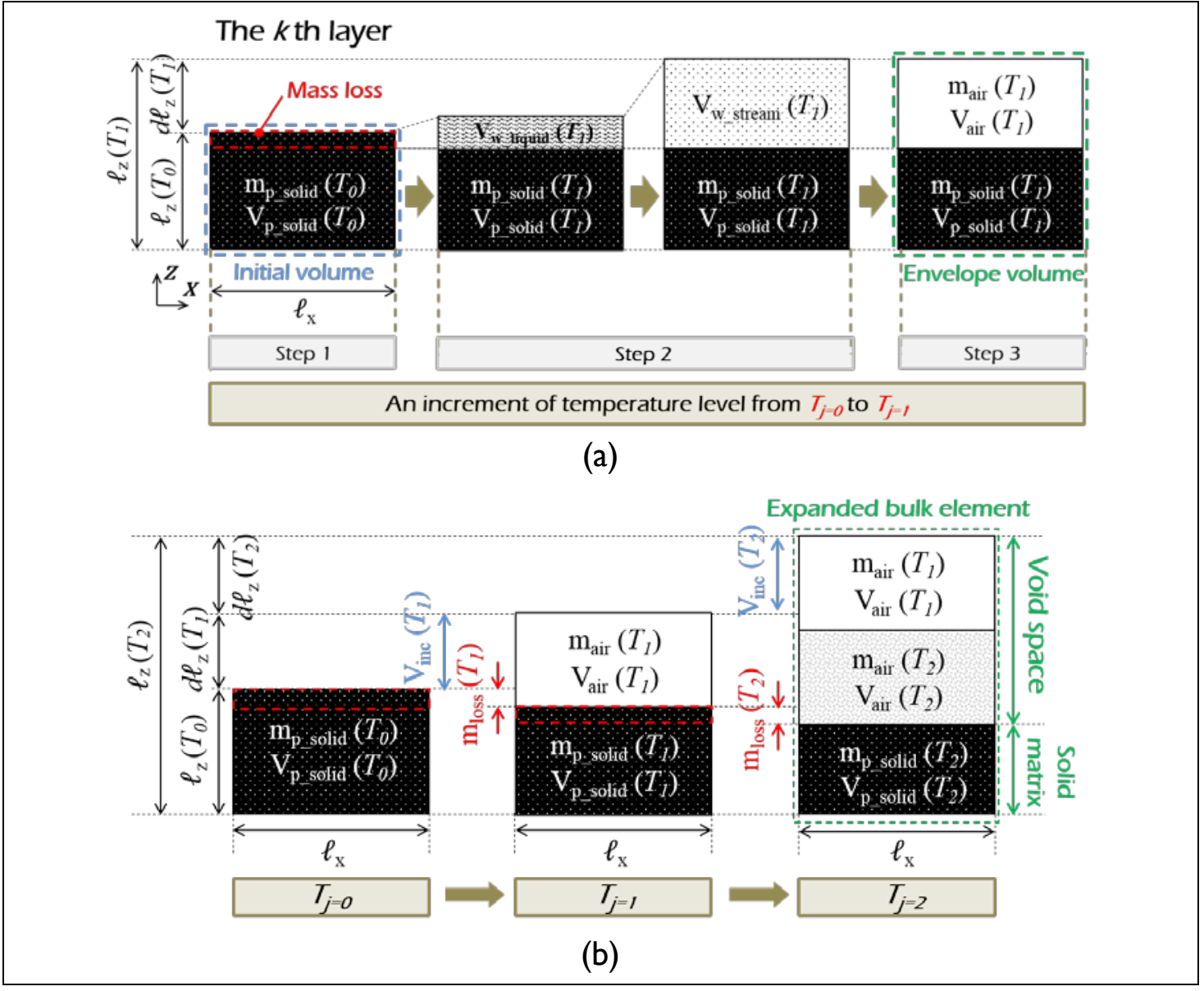

Figure 6. Sequential changes of mass and volume of the kth layer: (a) in a single increment of temperature and (b) in multi-increments of temperature. 


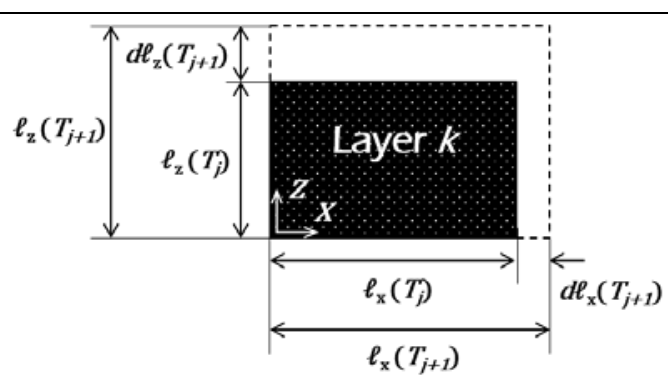

Figure 7. Two dimensional volume change of the kth layer over temperature.

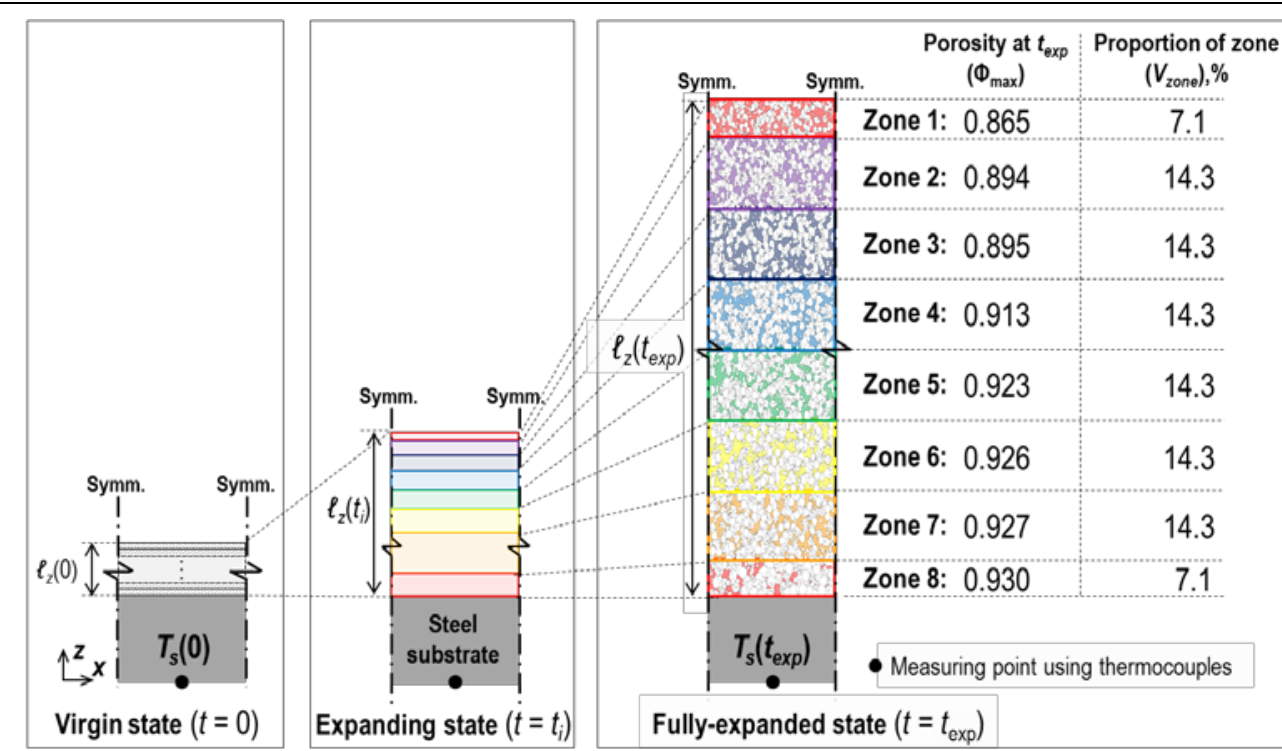

(a)

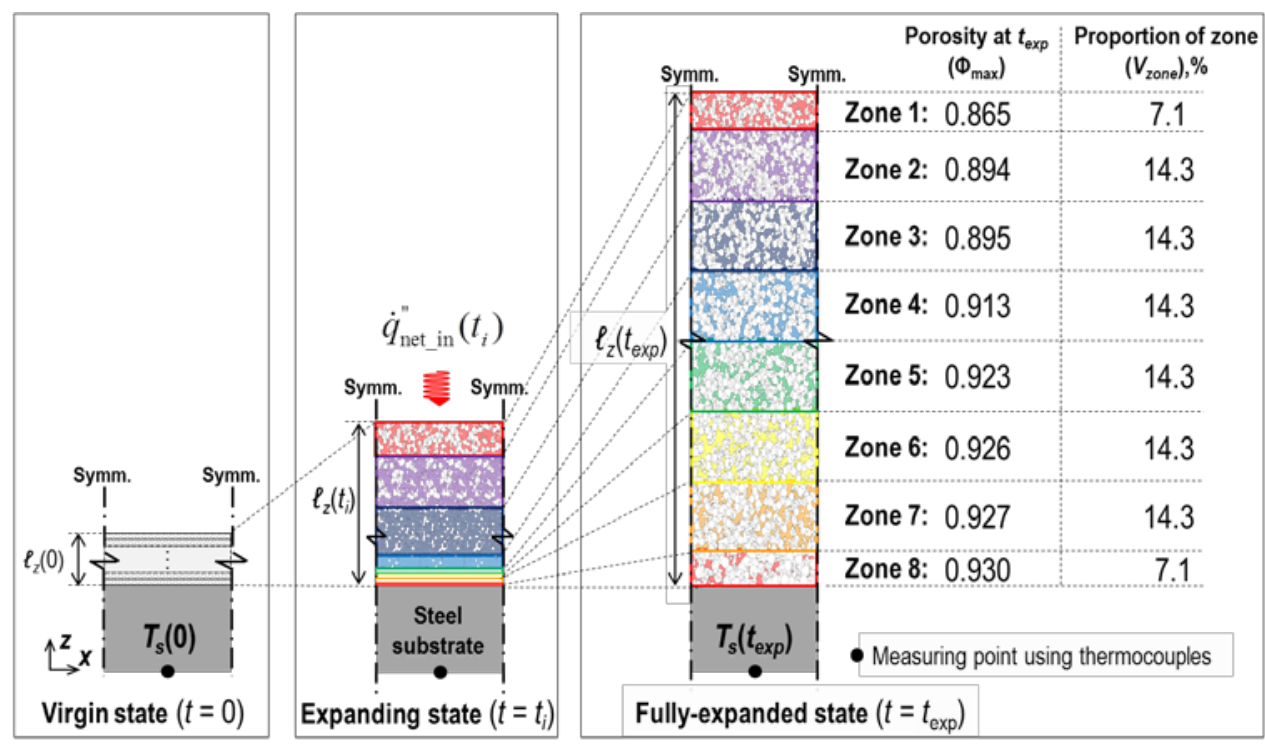

(b)

Figure 8. Schematics of intumescence of multilayer model: (a) virtual behaviour for description purposes and (b) true behaviour in cone calorimeter testing. 


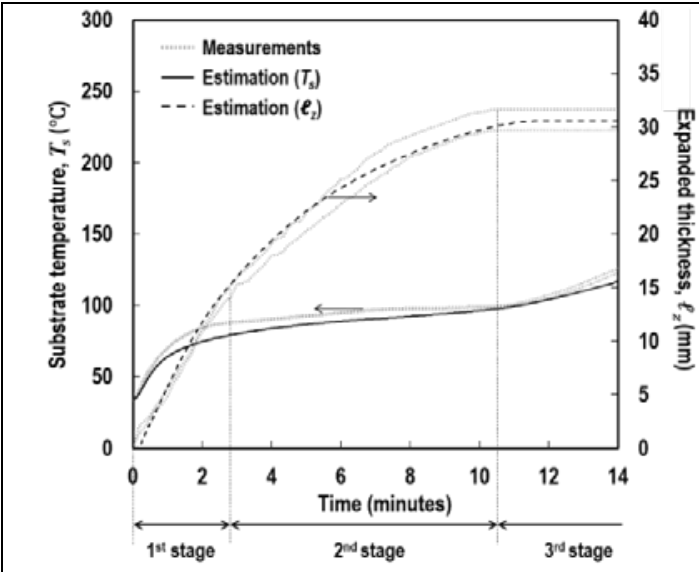

(a)

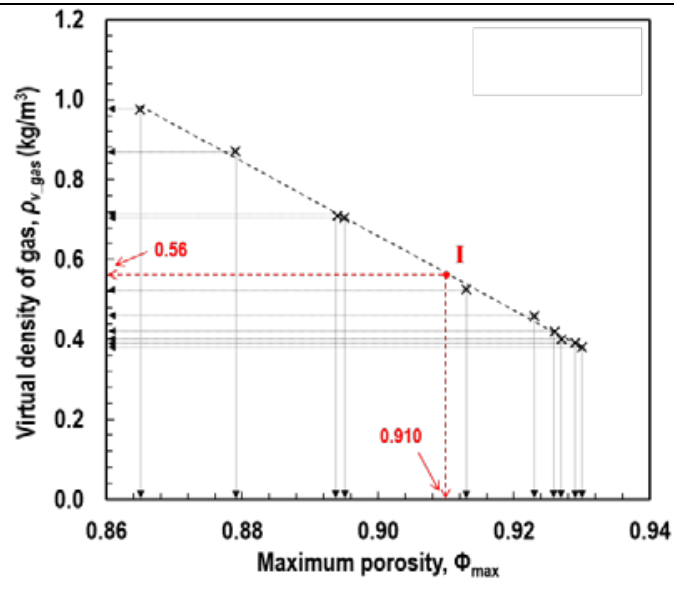

(b)

Figure 9. Determination of degree of expansion: (a) comparison between predictions and measurements and (b) linear relationship between $\rho_{v_{\_} g a s}$ and $\Phi_{\max }$.

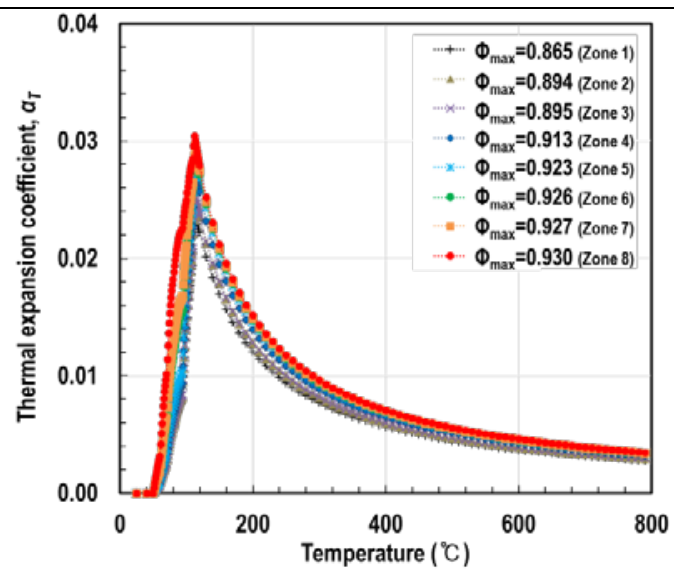

Figure 10. Temperature-dependent profile of $\left\{\alpha_{T}\right\}$.

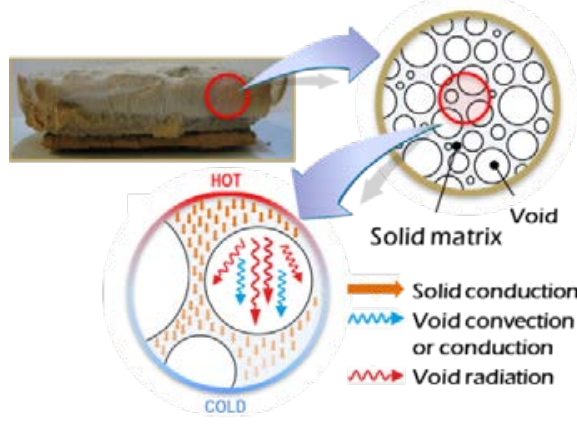

(a)

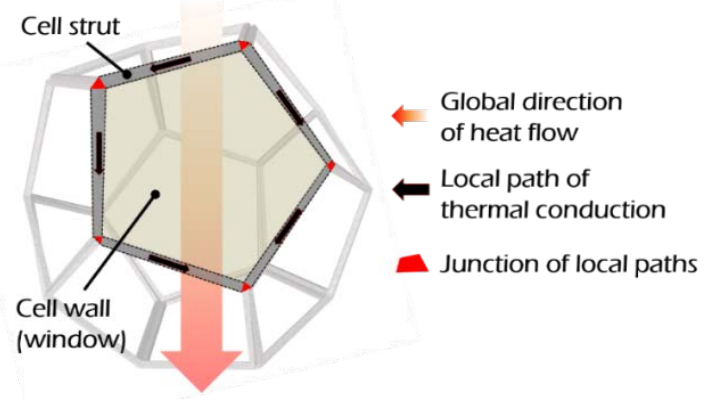

(b)

Figure I I. Conceptual diagrams: (a) heat transfer through internal porous structures of fully expanded intumescent systems, and (b) definitions of components of a unit pore's geometric structure. 


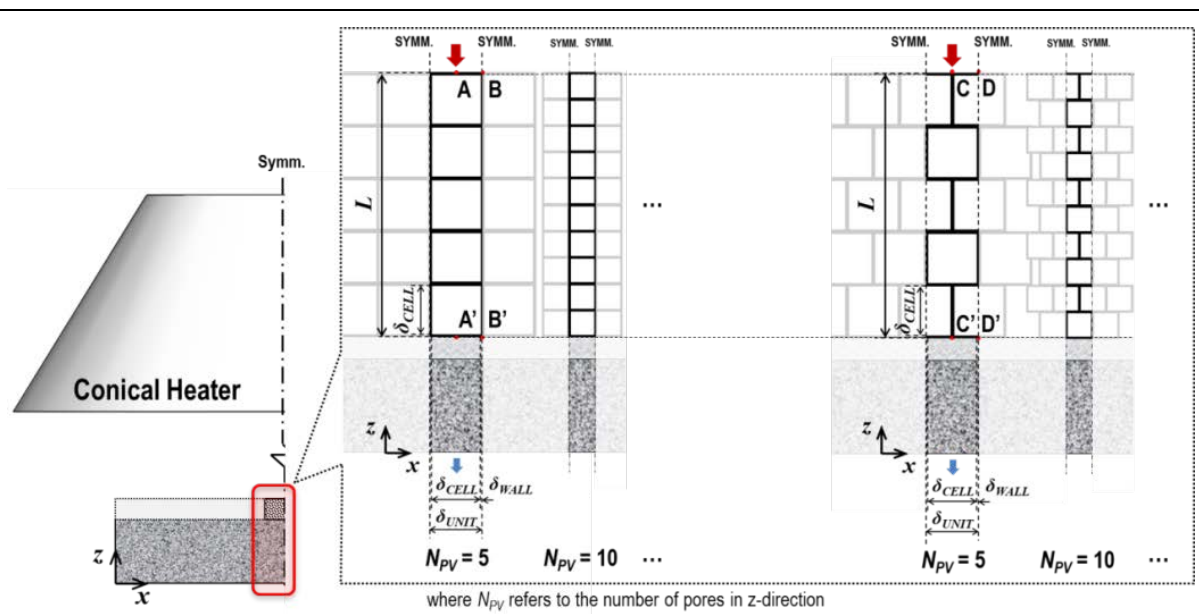

(a)

(b)

Figure 12. FEA multicellular models: (a) inline and (b) staggered formations [36].

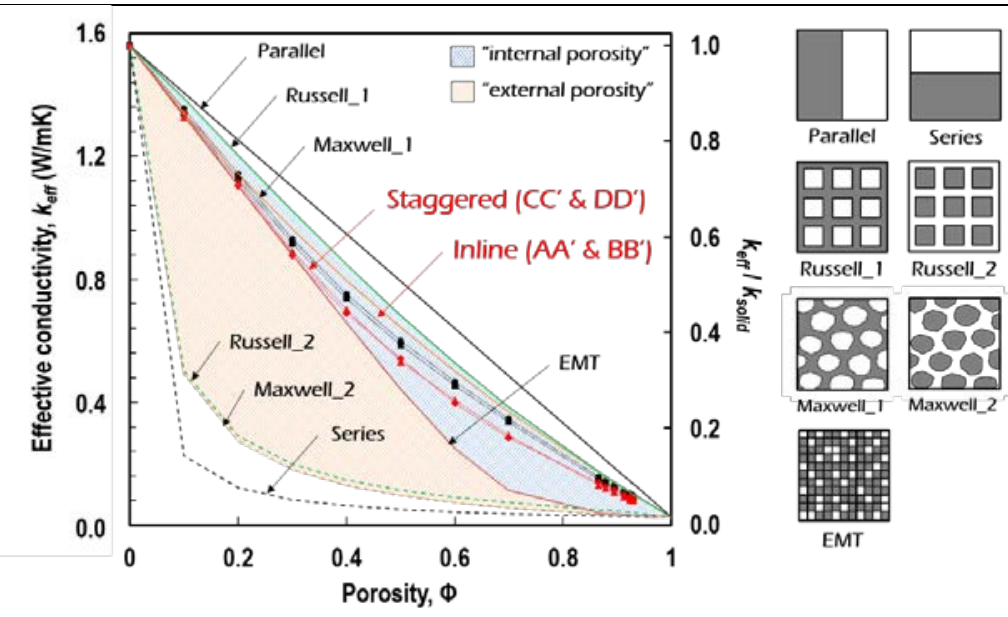

Figure 13. $\Phi-k_{\text {eff }}$ relations, obtained from multicellular simulations, with existing generic models [36].

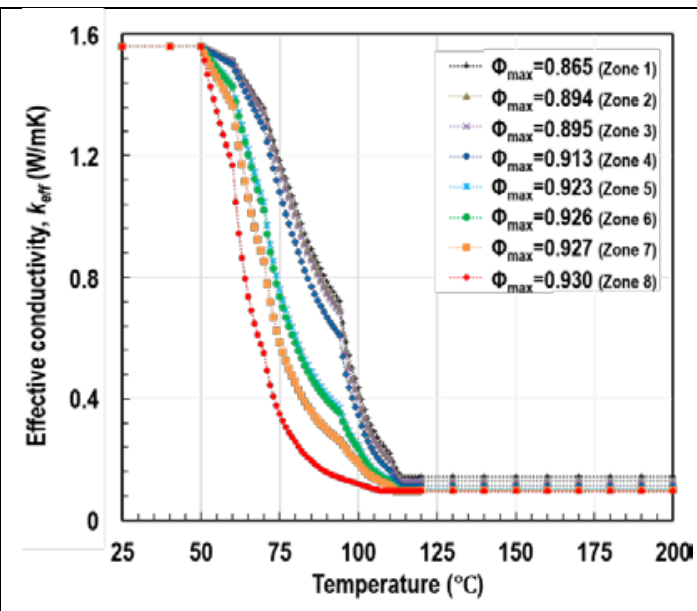

(a)

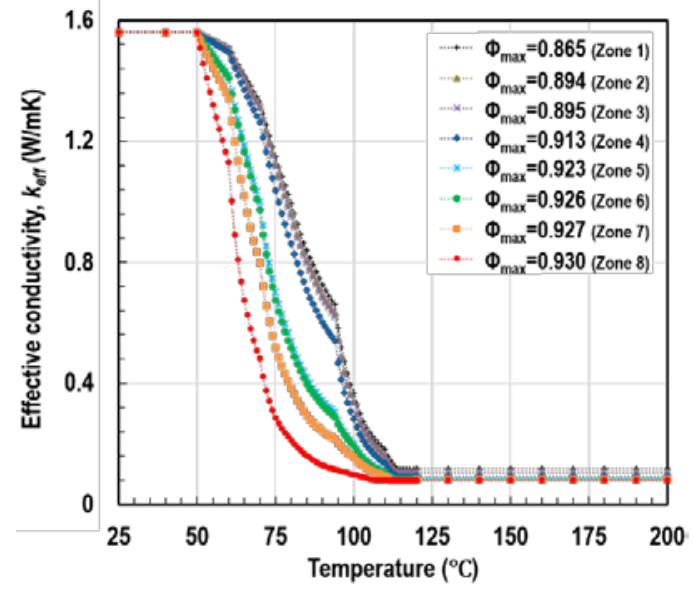

(b)

Figure I4. $T_{\mathrm{e}}-k_{\text {eff }}$ relationships: (a) upper and (b) lower bounds. 


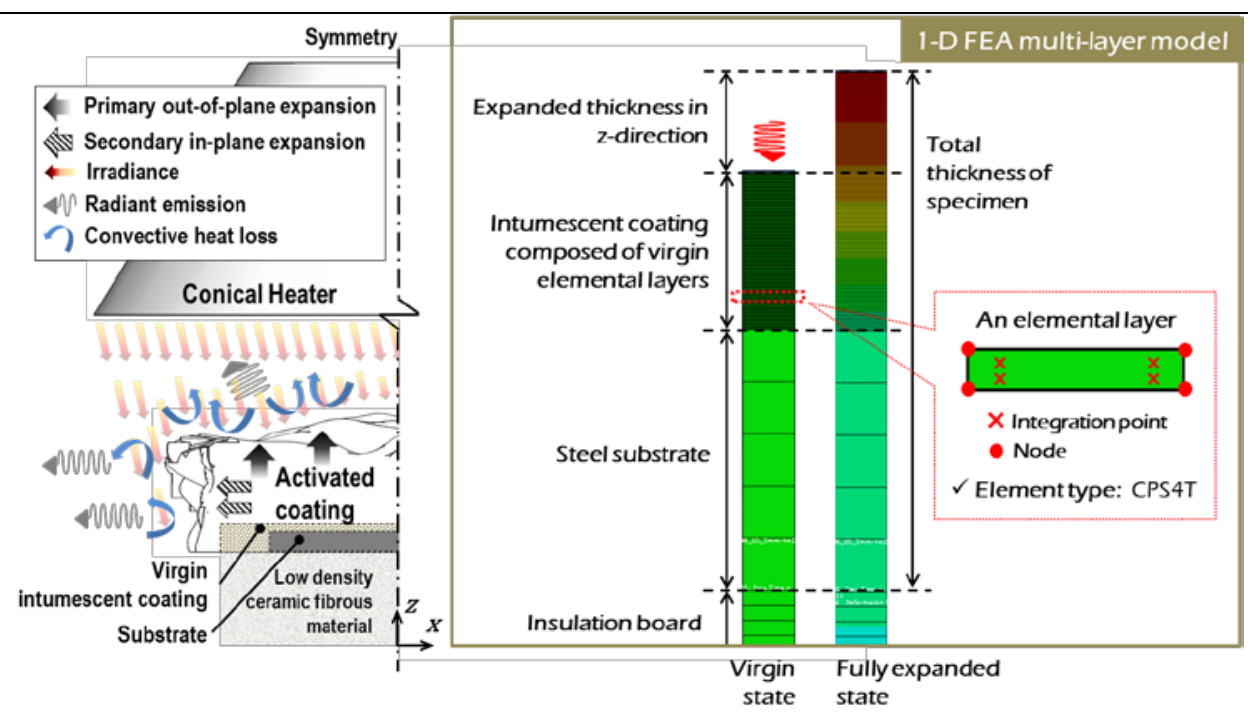

(a)
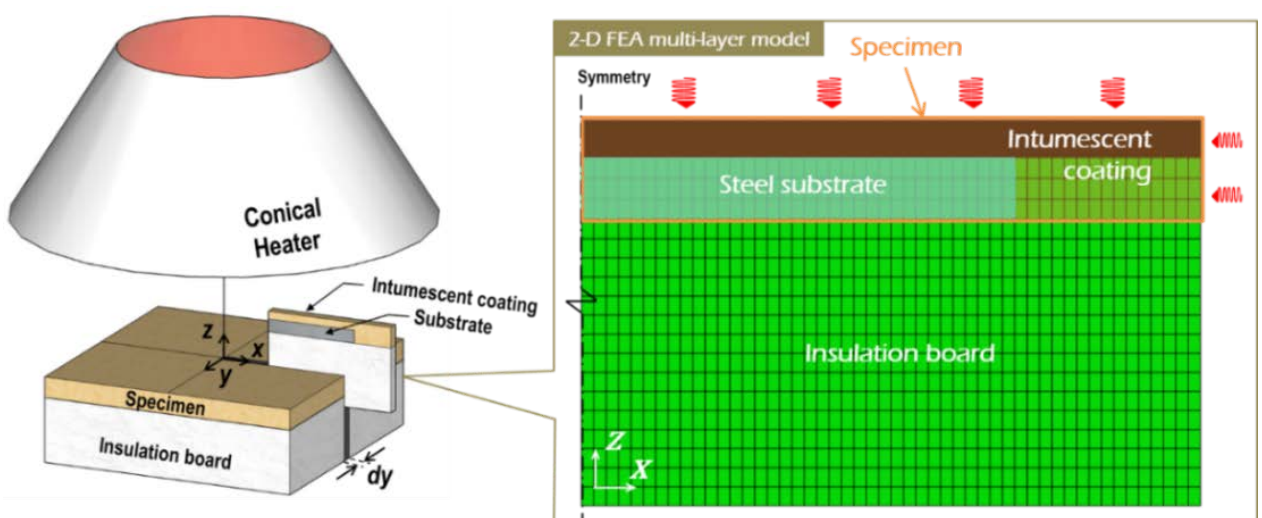

(b)

Figure I5. Geometries of FEA multi-layer models: (a) I-D, and (b) 2-D.

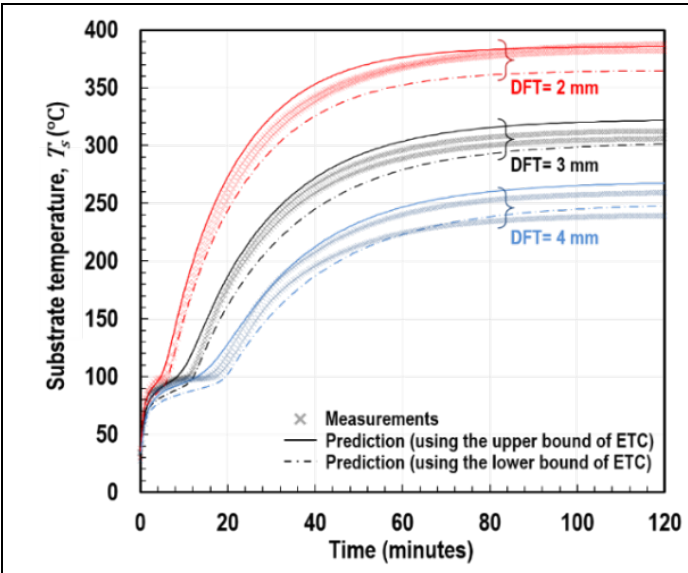

(a)

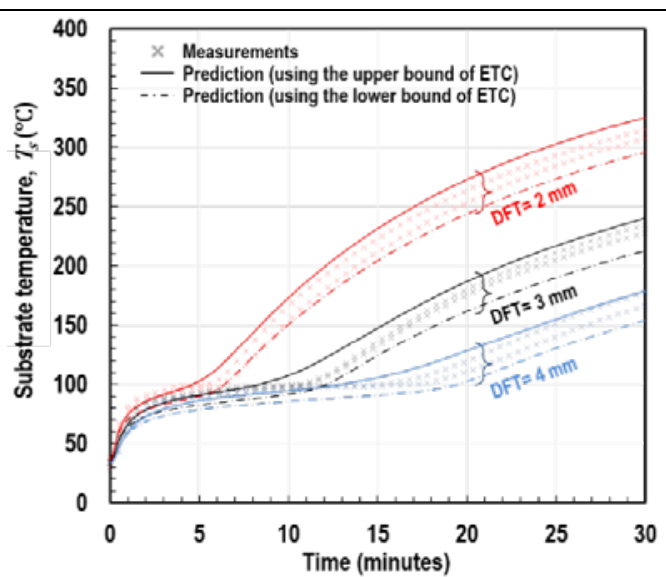

(b)

Figure 16. Substrate temperature development over time at $\dot{q}_{i r r}^{\prime \prime}=50 \mathrm{~kW} / \mathrm{m}^{2}$ : (a) overall and (b) initial stage. 


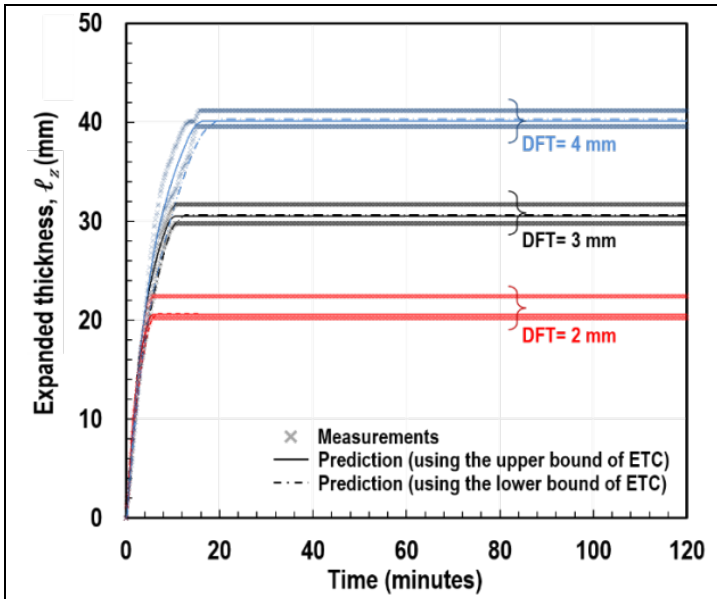

(a)

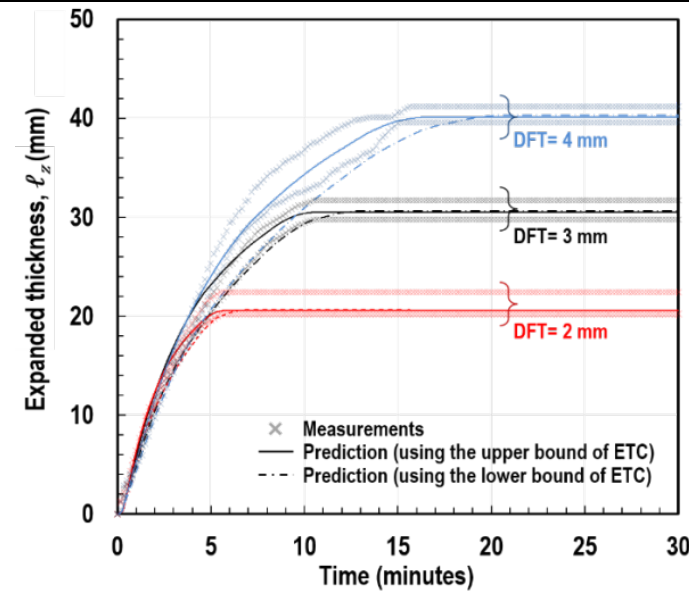

(b)

Figure 17. Coating expansion over time at $\dot{q}_{i r r}^{\prime \prime}=50 \mathrm{~kW} / \mathrm{m}^{2}$ : (a) overall and (b) initial stage.

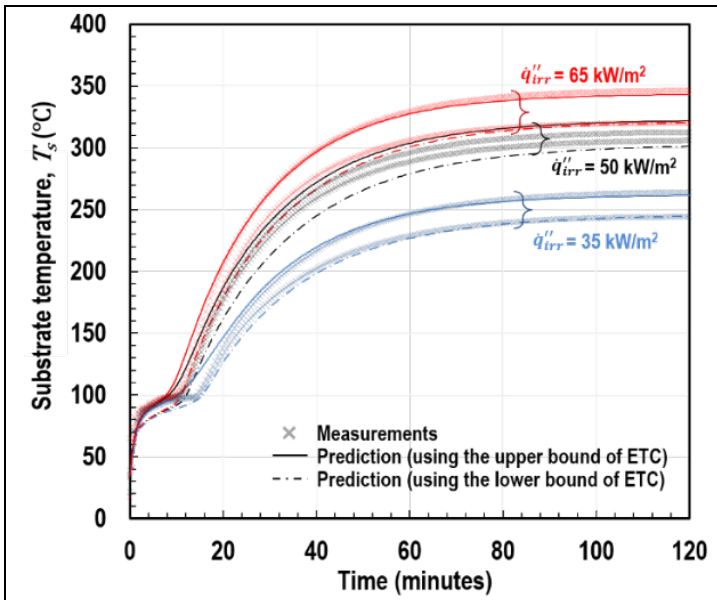

(a)

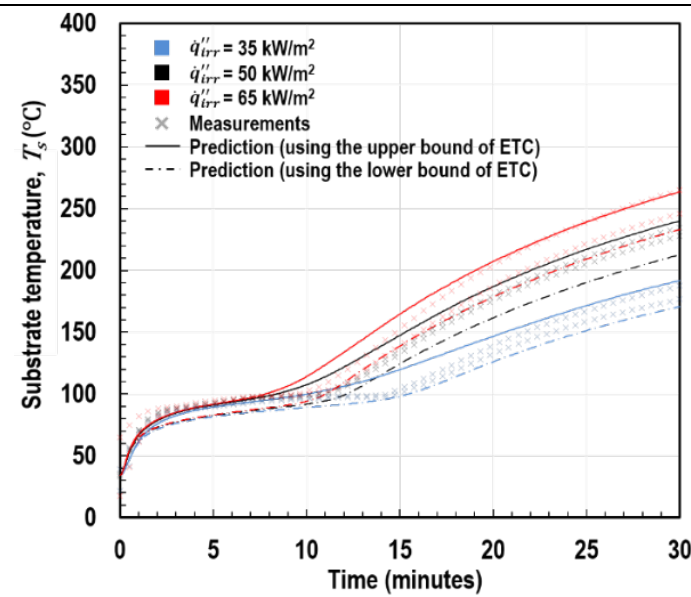

(b)

Figure 18. Substrate temperature development over time at DFT=3 mm: (a) overall and (b) initial stage. 


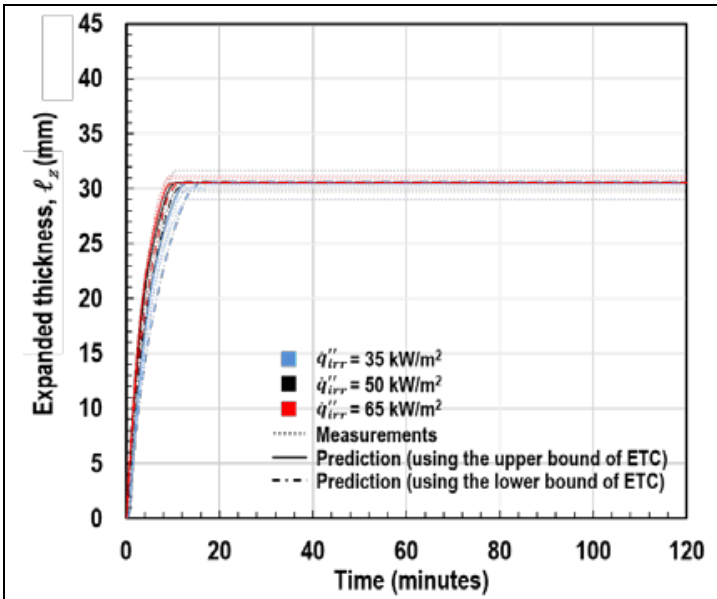

(a)

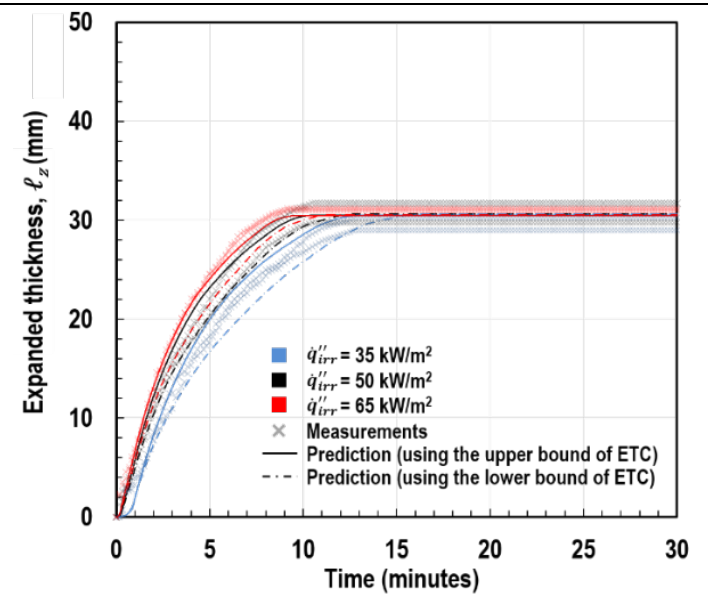

(b)

Figure 19. Coating expansion over time at DFT=3 mm: (a) overall and (b) initial stage.

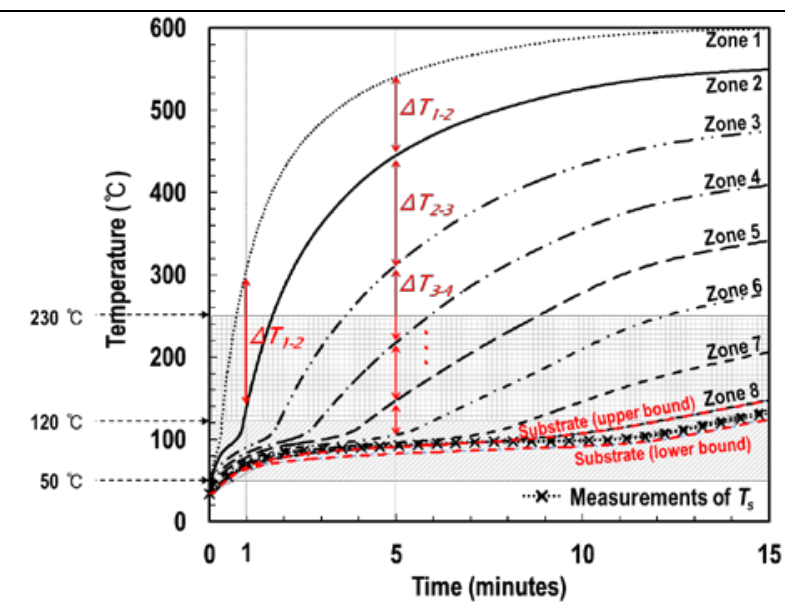

(a)

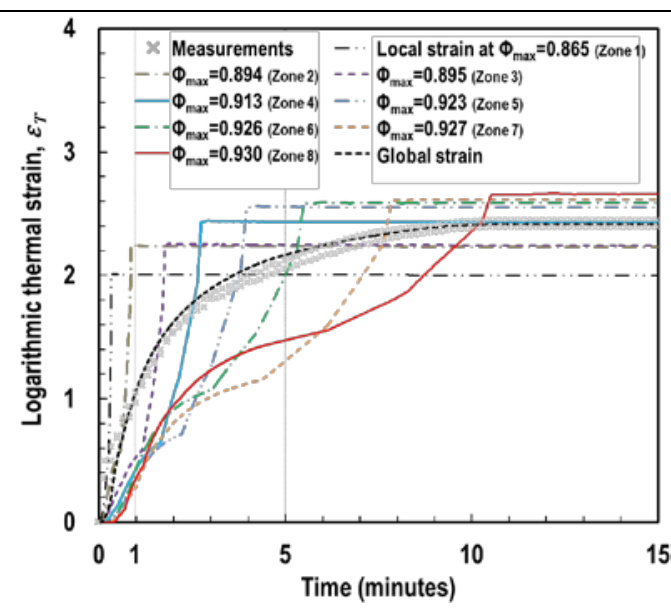

(b)

Figure 20. Numerical results obtained at DFT $=3 \mathrm{~mm}$ and $\dot{q}_{i r r}^{\prime \prime}=50 \mathrm{~kW} / \mathrm{m}^{2}$ : histories of (a) temperature and (b) logarithmic thermal strain of elemental layers. 


\section{TABLE}

Table I. Thermo-physical properties of materials and convective coefficients in cone testing.

\begin{tabular}{|c|c|c|c|c|c|}
\hline Materials & $\begin{array}{l}\text { Conductivity } \\
k(\mathrm{~W} /(\mathrm{mK}))\end{array}$ & $\begin{array}{c}\text { Density } \\
\rho_{d}\left(\mathrm{~kg} / \mathrm{m}^{3}\right)\end{array}$ & $\begin{array}{l}\text { Specific } \\
\text { heat c } \\
(\mathrm{J} /(\mathrm{kgK}))\end{array}$ & $\begin{array}{l}\text { Emissivity } \\
\varepsilon \varepsilon\end{array}$ & $\begin{array}{l}\text { Convective } \\
\text { coefficient, } \\
h\left(\mathrm{~W} /\left(\mathrm{m}^{2} \mathrm{~K}\right)\right)\end{array}$ \\
\hline $\begin{array}{l}\text { Intumescent } \\
\text { coating }\end{array}$ & Figure 14 & Figure 2(c) & Figure 2(b) & $0.77^{6}$ & \\
\hline $\begin{array}{c}\text { Steel plate' } \\
\text { Air }^{2}\end{array}$ & $\begin{array}{c}53.30 \\
0.03\end{array}$ & $\begin{array}{l}7870 \\
1.16\end{array}$ & $\begin{array}{c}440 \\
1007\end{array}$ & $\begin{array}{l}- \\
-\end{array}$ & $\begin{array}{l}14.6^{4} / \\
13.7^{5}\end{array}$ \\
\hline $\begin{array}{l}\text { Insulation } \\
\text { board }^{3}\end{array}$ & 0.21 & 900 & 1000 & 0.90 & \\
\hline
\end{tabular}

' Mild steel element (AISI CI020)

${ }^{2}$ Standard air properties

${ }^{3}$ High-performance insulation board (Promatech-T produced by Promat)

${ }^{4}$ Coefficient for turbulent free convection adjacent to a horizontal upward-facing surface [36]

${ }^{5}$ Coefficient for laminar free convection adjacent to a vertical surface [36]

${ }^{6}$ Hemispherical total emissivity [36] 